\title{
Sound Radiation and Vibration of Composite Panels Excited by Turbulent Flow: Analytical Prediction and Analysis
}

\author{
Joana Rocha \\ Department of Mechanical and Aerospace Engineering, Carleton University, Ottawa, ON, Canada K1S 5B6 \\ Correspondence should be addressed to Joana Rocha; joana.rocha@carleton.ca
}

Received 23 November 2013; Accepted 31 March 2014; Published 28 April 2014

Academic Editor: Valder Steffen Jr.

Copyright ( 2014 Joana Rocha. This is an open access article distributed under the Creative Commons Attribution License, which permits unrestricted use, distribution, and reproduction in any medium, provided the original work is properly cited.

\begin{abstract}
The present study investigates the vibration and sound radiation by panels exited by turbulent flow and by random noise. Composite and aluminum panels are analyzed through a developed analytical framework. The main objective of this study is to identify the difference between the vibroacoustic behaviour of these two types of panels. This topic is of particular importance, given the growing interest in applying composite materials for the construction of aircraft structures, in parts where aluminum panels were traditionally being used. An original mathematical framework is presented for the prediction of noise and vibration for composite panels. Results show the effect of panel size, thickness of core, and thickness of face layers on the predictions. Smaller composite panels generally produced lower levels of sound and vibration than longer and wider composite panels. Compared with isotropic panels, the composite panels analyzed generated lower noise levels, although it was observed that noise level was amplified at certain frequencies.
\end{abstract}

\section{Introduction}

The shift towards composite aircraft fuselage and wing structures and the overall use of new concepts of materials in aircraft manufacturing carry the need of a better understanding of structural and acoustic behaviors associated with these types of materials. The present study provides a novel analytical framework for the prediction of the vibroacoustic behaviour of composite panels. Previous models were developed and validated by the author aiming at the prediction of the vibroacoustic behaviour of flow-excited isotropic panels [1-4]. The present work adds a step forward to the previous models, by advancing the predictive models towards the application and analysis of composite panels' behaviour. As also shown in previous analysis, the mathematical approach presented has the ability to provide the fast and accurate prediction for various kinds of structural panels, specifically varying panels' structural properties, panels' size, thickness, number of layers, and airflow regimes. With the growing interest in composite materials in several fields, the research presented in this study can be useful for a broad range of applications, such as aerospace applications, automotive industry, civil engineering, and high-speed boats, in which the mechanical behaviour of the material should be well understood.

This study considers the case of a turbofan aircraft at cruise flight conditions, a situation in which interior noise levels are governed by the transmitted turbulent boundary layer noise into the cabin. It is known that chronic noise pollution exposure can cause hearing loss, and sleep and speech interference. In this context, it is desired that the fuselage structure provides appropriate noise attenuation so interior noise levels are within reasonable levels. This proper noise attenuation can only be achieved if the fuselage structure, hence fuselage panels, has appropriate strength, mass, and damping properties. Therefore, a need exists to better understand noise transmission properties of composite structures, such that they can be safely applied to aircraft.

The panels are considered to be simply supported in their four edges and excited by the turbulent boundary layer (TBL). Different composite structures were studied. As in [1-4], a combination of the Corcos model $[5,6]$ and Efimtsov model [7] was used to provide the TBL excitation to the panels and results obtained for the power spectral density (PSD) of the panels' vibrational and acoustical responses. Therefore, this study provides an original approach to the dynamical 


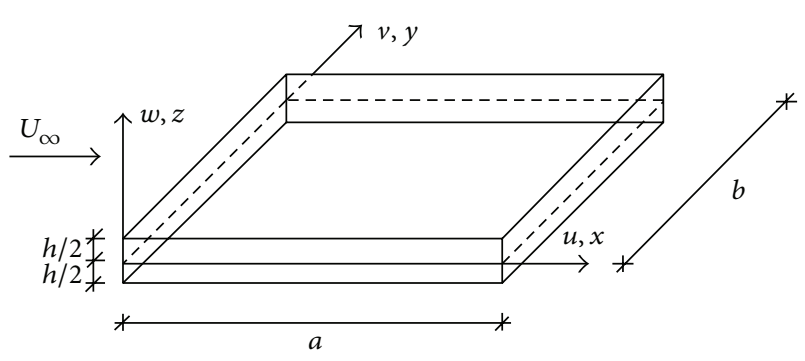

FIGURE 1: Scheme of the composite panel excited by turbulent flow.

response behaviour of composite structures, which is typically obtained only for free vibration conditions or for an acoustic sine wave harmonic excitation, as discussed in more detail in the following paragraphs. Previous studies have been conducted to understand the dynamic, vibration, and noise radiation properties by composite panels; however, most studies did not consider the turbulent flow excitation in the analysis.

Early studies $[8,9]$ have been established to compute the dynamic properties of laminated plates. In these studies, closed form exact solutions have been presented to calculate the natural frequencies of orthotropic, antisymmetric angle-ply and antisymmetric cross-ply laminated plates, with simply supported edges. One of the most popular methods to obtain approximate solutions for the frequencies of an orthotropic plate is the Rayleigh-Ritz method. Several authors [10-13] have investigated analytical methods to determine the sound transmission loss of sandwich structures, considering the case of an infinite plate excited by a plane wave. Later, in [14], these studies were extended for the prediction of sound transmission loss of infinite sandwich composite panels excited by a diffuse field. Two models were developed and compared: a symmetrical laminate composite and a discrete thick laminate composite.

Few studies have also been published focusing on the acoustic behaviour of finite sandwich structures. In [15], an analytical method is proposed to evaluate the sound insulation behaviour of sandwich panels containing two orthotropic cover plates and a core. In [16], a variational model, using the Rayleigh-Ritz method, is presented for the vibroacoustic analysis of a plate covered by a free or a constrained viscoelastic layer, immersed in either a light or a heavy fluid. The study in [17] presents a numerical method for the prediction of the acoustic and vibration responses of sandwich panels, based on the finite element formulation and coupled to a variational boundary element method to account for fluid loading. The plates were excited by acoustic plane waves or by a diffusive sound field. The main disadvantage of this method was the high computational time associated with the finite element discretization procedure. In a later study [18], the same authors presented a more efficient formulation based on a modal approach to analyze the vibration and acoustic behaviours of damped sandwich panels, subjected to mechanical and/or acoustic harmonic excitations.

The numerical techniques using either one or the combination of finite element method (FEM) with boundary

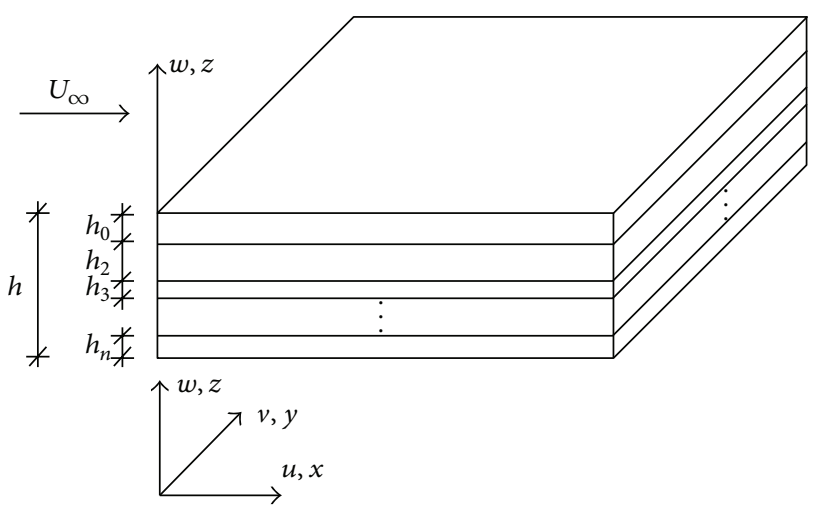

FIGURE 2: View of the anatomy of the composite ply layers.

element method (BEM) have been widely used for the purpose of identifying sound transmission characteristics of composite panels, for example, in [19-21]. However, in the high frequency analysis these methods often require a large number of FEM/BEM meshes, ultimately resulting in high computational costs. In [22], a hybrid analytical one-dimensional finite element method is derived, which uses FEM approximation in the thickness direction and analytical solutions in the plane directions, thus reducing the number of finite elements required. In this context, the present study addresses this problem through an analytical approach. Empirical models are used to provide the TBL flow excitation, while the radiated sound power is calculated by integrating the panel's structural vibration response, obtained from the analytical model. The model can be applied for a large variety of composite panels, and a large number of panel layers' configurations, with the advantage of providing an accurate and fast prediction without high computational costs. Results for the acoustical and vibration responses are shown for composite panels excited by the turbulent boundary layer and by a random excitation, which, as referred earlier, is a case study that was not investigated previously. A discussion is then presented on the comparison of the vibroacoustic behaviour of composite panels compared to traditional isotropic panels.

\section{Theoretical Formulation}

Consider the composite plate as shown in Figures 1 and 2. Each layer is considered to have an arbitrary thickness, $h_{i}$, and material properties, which may be defined by the user. The plate is assumed to be simply supported in all four boundaries, and the $(x, y)$ is its reference plane. The top surface of the sandwich panel is excited by turbulent flow or by random noise, as explained in more detail in the following section. Additionally, panel displacements are assumed to be small compared with the thickness of the panel.

2.1. Plate Governing Equations. From the theory and equations of mechanics of laminated composites, the displacement components $u, v$, and $w$ at a given point in the plate, 


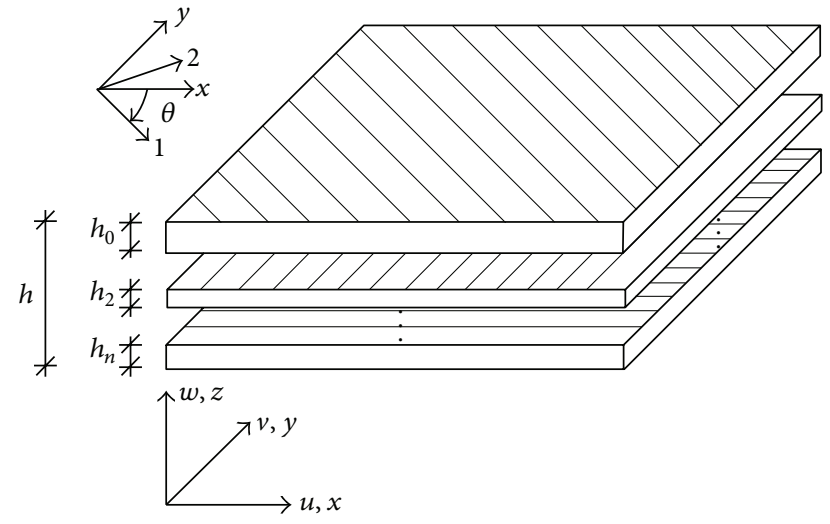

FIGURE 3: Detailed view of the anatomy of the composite ply layers.

respectively, in the $x, y$, and $z$ directions (as in Figure 2), can be written as follows:

$$
\begin{gathered}
u=u_{0}-z \frac{\partial w(x, y, t)}{\partial x} \\
v=v_{0}-z \frac{\partial w(x, y, t)}{\partial y} \\
w=w(x, y, t)
\end{gathered}
$$

in which $u_{0}$ and $v_{0}$ denote the displacements of the midplane of the plate in the $x$ and $y$ directions, respectively. The strains in the plate can then be written as functions of the displacement as follows in the vector form:

$$
\left(\begin{array}{c}
\epsilon_{x} \\
\epsilon_{y} \\
\gamma_{x y}
\end{array}\right)=\left(\begin{array}{c}
\frac{\partial u}{\partial x} \\
\frac{\partial v}{\partial y} \\
\frac{\partial u}{\partial y}+\frac{\partial v}{\partial x}
\end{array}\right)=\left(\begin{array}{c}
\frac{\partial u_{0}}{\partial x}-z \frac{\partial^{2} w}{\partial x^{2}} \\
\frac{\partial v_{0}}{\partial x}-z \frac{\partial^{2} w}{\partial y^{2}} \\
\frac{\partial u_{0}}{\partial y}+\frac{\partial v_{0}}{\partial x}-2 z \frac{\partial^{2} w}{\partial x \partial y}
\end{array}\right)
$$

The above equations are all written in the global coordinate systems $(x, y, z)$. Stresses in the ply or lamina coordinate system $(1,2,3)$ can then be written with relation to the stresses in the plate coordinate system as follows:

$$
\left(\begin{array}{c}
\sigma_{1} \\
\sigma_{2} \\
\tau_{12}
\end{array}\right)=\left[T_{i}\right]\left(\begin{array}{c}
\sigma_{x} \\
\sigma_{y} \\
\tau_{x y}
\end{array}\right)
$$

in which $\left[T_{i}\right]$ is the transformation matrix for the $i$ th ply, defined by

$$
\left[T_{i}\right]=\left[\begin{array}{ccc}
\cos ^{2} \theta_{i} & \sin ^{2} \theta_{i} & 2 \sin \theta_{i} \cos \theta_{i} \\
\sin ^{2} \theta_{i} & \cos ^{2} \theta_{i} & -2 \sin \theta_{i} \cos \theta_{i} \\
-\sin \theta_{i} \cos \theta_{i} & \sin \theta_{i} \cos \theta_{i} & \cos ^{2} \theta_{i}-\sin ^{2} \theta_{i}
\end{array}\right],
$$

and $\theta_{i}$ is the angle between the plate global coordinate system and the $i$ th ply coordinate system, as shown in Figure 3. Similarly, for strain, one can write

$$
\left(\begin{array}{c}
\epsilon_{1} \\
\epsilon_{2} \\
\gamma_{12}
\end{array}\right)=\left[T_{i}\right]\left(\begin{array}{c}
\epsilon_{x} \\
\epsilon_{y} \\
\gamma_{x y}
\end{array}\right)
$$

Additionally, stress and strain components in the ply coordinate system are related through the reduced stiffness matrix, $\left[Q_{i}\right]$, as follows:

$$
\left(\begin{array}{c}
\sigma_{1} \\
\sigma_{2} \\
\tau_{12}
\end{array}\right)=\left[Q_{i}\right]\left(\begin{array}{c}
\epsilon_{1} \\
\epsilon_{2} \\
\gamma_{12}
\end{array}\right)
$$

in which

$$
\left[Q_{i}\right]=\left[\begin{array}{ccc}
Q_{11}^{i} & Q_{12}^{i} & 0 \\
Q_{21}^{i} & Q_{22}^{i} & 0 \\
0 & 0 & Q_{66}^{i}
\end{array}\right]
$$

with

$$
\begin{gathered}
Q_{11}^{i}=\frac{E_{1}^{i}}{1-v_{12}^{i} v_{21}^{i}}, \\
Q_{22}^{i}=\frac{E_{2}^{i}}{1-v_{12}^{i} \nu_{21}^{i}}, \\
Q_{12}^{i}=\frac{v_{12}^{i} E_{2}^{i}}{1-v_{12}^{i} v_{21}^{i}}, \\
Q_{66}^{i}=G_{12}^{i},
\end{gathered}
$$

where $E_{1}^{i}$ and $E_{2}^{i}$ are the $i$ th ply elasticity modulus in the longitudinal and transverse direction of the fibers, respectively, $v_{12}^{i}$ and $\nu_{21}^{i}$ are Poisson's ratios for the $i$ th ply, and $G_{12}^{i}$ is the $i$ th ply shear modulus. Combining (3) through (11), one can write the following relationship relating stress and strain in the plate coordinate system, based on each ply reduced stiffness matrix components and transformation matrix components:

$$
\left(\begin{array}{c}
\sigma_{x} \\
\sigma_{y} \\
\tau_{x y}
\end{array}\right)=\left[\bar{Q}_{i}\right]\left(\begin{array}{c}
\epsilon_{x} \\
\epsilon_{y} \\
\gamma_{x y}
\end{array}\right)
$$


where

$$
\begin{aligned}
& {\left[\bar{Q}_{i}\right]=\left[T_{i}^{-1}\right]\left[Q_{i}\right]\left[T_{i}\right]=\left[\begin{array}{lll}
\bar{Q}_{11}^{i} & \bar{Q}_{12}^{i} & \bar{Q}_{16}^{i} \\
\bar{Q}_{12}^{i} & \bar{Q}_{22}^{i} & \bar{Q}_{26}^{i} \\
\bar{Q}_{16}^{i} & \bar{Q}_{26}^{i} & \bar{Q}_{66}^{i}
\end{array}\right],} \\
& \bar{Q}_{11}^{i}=Q_{11}^{i} m_{i}^{4}+2\left(Q_{12}^{i}+2 Q_{66}^{i}\right) m_{i}^{2} n_{i}^{2}+Q_{22}^{i} n_{i}^{4}, \\
& \bar{Q}_{12}^{i}=\left(Q_{11}^{i}+Q_{22}^{i}-4 Q_{66}^{i}\right) m_{i}^{2} n_{i}^{2}+Q_{12}^{i}\left(m_{i}^{4}+n_{i}^{4}\right) \text {, } \\
& \bar{Q}_{22}^{i}=Q_{11}^{i} n_{i}^{4}+2\left(Q_{12}^{i}+2 Q_{66}^{i}\right) m_{i}^{2} n_{i}^{2}+Q_{22}^{i} m_{i}^{4}, \\
& \bar{Q}_{16}^{i}=\left(Q_{11}^{i}-Q_{12}^{i}-2 Q_{66}^{i}\right) m_{i}^{3} n_{i}+\left(Q_{12}^{i}-Q_{22}^{i}+2 Q_{66}^{i}\right) m_{i} n_{i}^{3}, \\
& \bar{Q}_{26}^{i}=\left(Q_{11}^{i}-Q_{12}^{i}-2 Q_{66}^{i}\right) m_{i} n_{i}^{3}+\left(Q_{12}^{i}-Q_{22}^{i}+2 Q_{66}^{i}\right) m_{i}^{3} n_{i}, \\
& \bar{Q}_{66}^{i}=\left(Q_{11}^{i}+Q_{22}^{i}-2 Q_{12}^{i}-2 Q_{66}^{i}\right) m_{i}^{2} n_{i}^{2}+Q_{66}^{i}\left(m_{i}^{4}+n_{i}^{4}\right), \\
& c\left(N_{x} \frac{\partial^{2} w}{\partial x^{2}}+2 N_{x y} \frac{\partial^{2} w}{\partial x \partial y}+N_{y} \frac{\partial^{2} w}{\partial y^{2}}\right) \\
& +\left(\frac{\partial^{2} M_{x}}{\partial x^{2}}+2 \frac{\partial^{2} M_{x y}}{\partial x \partial y}+M_{y} \frac{\partial^{2} w}{\partial y^{2}}\right)+f_{z}=\sum_{i=1}^{n} \rho_{i} h_{i} \frac{\partial^{2} w}{\partial t^{2}},
\end{aligned}
$$

in which $f_{z}=-p_{\text {ext }}(x, y, t)$ is the external pressure applied to the panel due to the fluid flow or the random excitation, $\rho_{i}$ is the density of the $i$ th ply, and the stress resultant and moment resultant components are defined as functions of the stress components, respectively, as follows:

$$
\begin{gathered}
\left(\begin{array}{c}
N_{x} \\
N_{y} \\
N_{x y}
\end{array}\right)=\sum_{i=1}^{n} \int_{h_{i-1}}^{h_{i}}\left(\begin{array}{c}
\sigma_{x} \\
\sigma_{y} \\
\tau_{x y}
\end{array}\right) d z, \\
\left(\begin{array}{c}
M_{x} \\
M_{y} \\
M_{x y}
\end{array}\right)=\sum_{i=1}^{n} \int_{h_{i-1}}^{h_{i}}\left(\begin{array}{c}
\sigma_{x} \\
\sigma_{y} \\
\tau_{x y}
\end{array}\right) z d z .
\end{gathered}
$$

After substituting the stress components defined by (12) into (21) and making use of (14) through (19), then (20) can be transformed to the following form, as function of the plate displacement $w$ :

$$
\begin{aligned}
\frac{1}{3} \sum_{i=1}^{n}\left(h_{i}^{3}-h_{i-1}^{3}\right) & \\
\times & {\left[\bar{Q}_{11}^{i}\left(\frac{\partial^{2} w}{\partial x^{2}}\right)^{2}+\bar{Q}_{22}^{i}\left(\frac{\partial^{2} w}{\partial y^{2}}\right)^{2}\right.} \\
& +2 \bar{Q}_{12}^{i}\left(\frac{\partial^{2} w}{\partial x^{2}}\right)\left(\frac{\partial^{2} w}{\partial y^{2}}\right)+4 \bar{Q}_{16}^{i}\left(\frac{\partial^{2} w}{\partial x^{2}}\right)\left(\frac{\partial^{2} w}{\partial x \partial y}\right) \\
& \left.+4 \bar{Q}_{26}^{i}\left(\frac{\partial^{2} w}{\partial y^{2}}\right)\left(\frac{\partial^{2} w}{\partial x \partial y}\right)+4 \bar{Q}_{66}^{i}\left(\frac{\partial^{2} w}{\partial x \partial y}\right)^{2}\right] \\
+ & \frac{1}{3} \sum_{i=1}^{n}\left(h_{i}^{3}-h_{i-1}^{3}\right) \\
\times & {\left[\bar{Q}_{11}^{i} \frac{\partial^{4} w}{\partial x^{4}}+\bar{Q}_{22}^{i} \frac{\partial^{4} w}{\partial y^{4}}+6 \bar{Q}_{16}^{i} \frac{\partial^{4} w}{\partial x^{3} \partial y}\right.} \\
& \left.+6 \bar{Q}_{26}^{i} \frac{\partial^{4} w}{\partial x \partial y^{3}}+\left(2 \bar{Q}_{12}^{i}+8 \bar{Q}_{66}^{i}\right) \frac{\partial^{4} w}{\partial x^{2} \partial y^{2}}\right] \\
+ & \sum_{i=1}^{n} \rho_{i} h_{i} \frac{\partial^{2} w}{\partial t^{2}}=f_{z} .
\end{aligned}
$$

Each panel in the present study aims to represent the distance between adjacent stringers and frames in an aircraft fuselage; hence each individual panel is assumed to vibrate independently. In addition, since panels are considered to be flat and simply supported in all four boundaries, the panel's displacement can be defined as follows [23, 24]:

$$
w(x, y, t)=\sum_{m_{x}=1}^{M_{x}} \sum_{m_{y}=1}^{M_{y}} \alpha_{m_{x}}(x) \beta_{m_{y}}(y) q_{m_{x} m_{y}}(t),
$$

where $\alpha_{m_{x}}(x)$ and $\beta_{m_{y}}(y)$ are the spatial functions, defining the variation of $w(x, y, t)$ with $x$ and $y$, respectively, $q_{m_{x} m_{y}}(t)$ are the temporal functions, defining the variation of $w(x, y, t)$ with time, and $M=M_{x} \times M_{y}$ is the total number of plate modes $\left(m_{x}, m_{y}\right)$ considered. For simply supported plates, the spatial functions may be defined as follows:

$$
\begin{aligned}
& \alpha_{m_{x}}(x)=\sqrt{\frac{2}{a}} \sin \left(\frac{m_{x} \pi x}{a}\right), \\
& \beta_{m_{y}}(y)=\sqrt{\frac{2}{b}} \sin \left(\frac{m_{y} \pi y}{b}\right),
\end{aligned}
$$


where $a$ and $b$ are the dimensions of the plate in the $x$ and $y$ directions. Also, the natural frequencies for the simply supported plate can be determined by

$$
\begin{aligned}
\omega_{m_{x} m_{y}}=\frac{\pi^{2}}{\sqrt{\sum_{i=1}^{n} \rho_{i} h_{i}}} & {\left[D_{11}\left(\frac{m_{x}}{a}\right)^{4}+D_{22}\left(\frac{m_{y}}{b}\right)^{4}\right.} \\
& \left.+2\left(D_{12}+2 D_{66}\right)\left(\frac{m_{x}}{a}\right)^{2}\left(\frac{m_{y}}{b}\right)^{2}\right]^{1 / 2},
\end{aligned}
$$

in which

$$
D_{j k}=\sum_{i=1}^{n} \int_{h_{i-1}}^{h_{i}} \bar{Q}_{j k}^{i} z^{2} d z .
$$

Developing (22) by considering (23) to (25), making use of the orthogonality of the plate modes, and integrating over the plate area, similarly to the mathematical approach followed in [4], the equilibrium equation for an orthotropic plate is written in the matrix form, as

$$
\left[M_{p}\right] \ddot{\mathbf{q}}(t)+\left[D_{p}\right] \dot{\mathbf{q}}(t)+\left[K_{p}\right] \mathbf{q}(t)=\mathbf{p}_{\text {ext }}(t),
$$

where $\left[M_{p}\right],\left[D_{p}\right]$, and $\left[K_{p}\right]$ are mass, damping, and stiffness $M \times M$ matrices, respectively, and $\mathbf{q}(t), \dot{\mathbf{q}}(t)$, and $\ddot{\mathbf{q}}(t)$ are the position, velocity, and acceleration vectors, with components defined, respectively, as $q_{m}(t)=Q_{m} e^{i \omega t}, \dot{q}_{m}(t)=i Q_{m} \omega e^{i \omega t}$, and $\ddot{q}_{m}(t)=-Q_{m} \omega^{2} e^{i \omega t}$. After performing all the above described mathematical manipulations, it can be shown that each term in (28) is defined as follows:

$$
\begin{gathered}
{\left[M_{p}\right]=\operatorname{diag}\left[\sum_{i=1}^{n} \rho_{i} h_{i}\right],} \\
{\left[D_{p}\right]=\operatorname{diag}\left[2 \xi_{p} \omega_{m_{x} m_{y}} \sum_{i=1}^{n} \rho_{i} h_{i}\right],} \\
{\left[K_{p}\right]=\frac{1}{3} \sum_{i=1}^{n}\left(h_{i}^{3}-h_{i-1}^{3}\right)\left\{\bar{Q}_{11}^{i} \mathbf{I}(x)+\bar{Q}_{22}^{i} \mathbf{I}(y)\right.} \\
\left.+\left(2 \bar{Q}_{12}^{i}+8 \bar{Q}_{66}^{i}\right) \mathbf{I}^{\prime}(x) \mathbf{I}^{\prime}(y)\right\}, \\
\mathbf{p}_{\mathrm{ext}}(t)=\left[\int_{0}^{a} \int_{0}^{b} \alpha_{m_{x}}(x) \beta_{m_{y}}(y) p_{\mathrm{ext}}(x, y, t) d x d y\right],
\end{gathered}
$$

in which $\xi_{p}$ was added to account with the damping of the plate, and

$$
\begin{gathered}
\mathbf{I}(x)=\operatorname{diag}\left[\frac{1}{a}\left(\frac{m_{x} \pi}{a}\right)^{4}\right], \\
\mathbf{I}(y)=\operatorname{diag}\left[\frac{1}{b}\left(\frac{m_{y} \pi}{b}\right)^{4}\right], \\
\mathbf{I}^{\prime}(x)=-\frac{1}{a}\left(\frac{m_{x} \pi}{a}\right)^{2} \cos \left[\left(m_{x}-m_{x}^{\prime}\right) \pi\right], \\
\mathbf{I}^{\prime}(y)=-\frac{1}{b}\left(\frac{m_{y} \pi}{b}\right)^{2} \cos \left[\left(m_{y}-m_{y}^{\prime}\right) \pi\right] .
\end{gathered}
$$

2.2. Radiated Sound Power. The calculation of the panels' radiated sound power in the frequency domain requires a rearrangement of the time domain equations presented in (22). For this end, knowing that $q_{m}=Q_{m} e^{i \omega t}$ as previously described, one can write (28) in the following desired form in the frequency, $\omega$, domain:

$$
\mathbf{Y}(\omega)=\mathbf{H}(\omega) \mathbf{X}(\omega)
$$

where

$$
\begin{gathered}
\mathbf{Y}(\omega)=\mathbf{W}(\omega), \\
\mathbf{X}(\omega)=\mathbf{P}_{\mathrm{ext}}(\omega), \\
\mathbf{H}(\omega)=-\omega^{2}\left[M_{p}\right]+i \omega\left[D_{p}\right]+\left[K_{p}\right],
\end{gathered}
$$

in which $\mathbf{H}(\omega)$ is system frequency response matrix, $\mathbf{Y}(\omega)$ is the response of the system to the excitation $\mathbf{X}(\omega)$, and vectors $\mathbf{W}(\omega)$ and $\mathbf{P}_{\text {ext }}(\omega)$ correspond, respectively, to the vectors $\mathbf{q}(t)$ and $\mathbf{p}_{\text {ext }}(t)$, written in the frequency domain. Considering the turbulent boundary layer random excitation as a stationary and homogeneous function, the spectral density of the system response is given by $[25,26]$

$$
\mathbf{S}_{W W}(\omega)=\mathbf{H}^{*}(\omega) \mathbf{S}_{P P}(\omega) \mathbf{H}^{T}(\omega)
$$

where superscripts $*$ and $T$ denote Hermitian conjugate and matrix transpose, respectively, $\mathbf{S}_{P P}(\omega)$ is the spectral density matrix of the random excitation $\mathbf{P}_{\text {ext }}(\omega)$, and $\mathbf{S}_{W W}(\omega)$ is the spectral density matrix of the system response $\mathbf{W}(\omega)$. The matrix $S_{P P}(\omega)$ corresponds to the generalized power density matrix of the turbulent boundary layer excitation, defined by

$$
\begin{array}{r}
\mathbf{S}_{\mathrm{tbl}}(\omega)=\left[\iint_{0}^{a} \iint_{0}^{b} \alpha_{m_{x}}(x) \alpha_{m_{x}^{\prime}}\left(x^{\prime}\right) \beta_{m_{y}}(y) \beta_{m_{y}^{\prime}}\left(y^{\prime}\right)\right. \\
\left.\times S\left(\xi_{x}, \xi_{y}, \omega\right) d x d x^{\prime} d y d y^{\prime}\right],
\end{array}
$$

in which $S\left(\xi_{x}, \xi_{y}, \omega\right)$ is defined by Corcos model $[5,21]$ and $\xi_{x}=x-x^{\prime}$ and $\xi_{y}=y-y^{\prime}$ are the spatial separations in the streamwise and spanwise directions of the plate, respectively. As shown in [1-3], a combination of Corcos and Efimtsov models may be suitable to provide this excitation as follows:

$$
S\left(\xi_{x}, \xi_{y}, \omega\right)=S_{\mathrm{ref}}(\omega) e^{-\left(\alpha_{x} \omega\left|\xi_{x}\right| / U_{c}\right)} e^{-\left(\alpha_{y} \omega\left|\xi_{y}\right| / U_{c}\right)} e^{-\left(i \omega \xi_{x} / U_{c}\right)}
$$

where $U_{c}$ is the turbulent boundary layer convective velocity, $\alpha_{x}=0.1$ and $\alpha_{y}=0.77$ are empirical parameters used to provide the best agreement with the reality [27], and $S_{\text {ref }}(\omega)$ is defined using Efimtsov model [7]. In [1], an analytical form was derived for the matrix described in (34). The power spectral density function of the plate displacement can then 
be defined as functions of the above matrix, respectively, plate area as:

$$
\begin{aligned}
& S_{w w}\left(x_{1}, y_{1}, x_{2}, y_{2}, \omega\right) \\
& =\sum_{m_{x_{1}}, m_{x_{2}}=1}^{M_{x}^{2}} \sum_{m_{y_{1}}, m_{y_{2}}=1}^{M_{y}^{2}} \alpha_{m_{x_{1}}}\left(x_{1}\right) \alpha_{m_{x_{2}}}\left(x_{2}\right) \\
& \quad \times \beta_{m_{y_{1}}}\left(y_{1}\right) \beta_{m_{y_{2}}}\left(y_{2}\right) \mathbf{S}_{W W}(\omega)_{m_{1}, m_{2}},
\end{aligned}
$$

and the overall power spectral density function can be found by integrating the individual power spectral densities over the plate area displacement, as following:

$$
S_{w w}(\omega)=\iint_{0}^{a} \iint_{0}^{b} S_{w w}\left(x_{1}, y_{1}, x_{2}, y_{2}, \omega\right) d x_{1} d x_{2} d y_{1} d y_{2} .
$$

Analytical expressions for $S_{w w}\left(x_{1}, y_{1}, x_{2}, y_{2}, \omega\right)$ and $S_{w w}(\omega)$ were obtained in [23]. The power spectral density matrix of the plate velocity can be determined from the power spectral density matrix of the plate displacement as follows:

$$
\mathbf{S}_{V V}(\omega)=\omega^{2} \mathbf{S}_{W W}(\omega) .
$$

Using these analytical forms, the plate radiated sound power function and the overall power spectral density function can be determined, respectively as follows:

$$
\begin{gathered}
\operatorname{RSP}\left(x_{1}, y_{1}, x_{2}, y_{2}, \omega\right) \\
=\sum_{m_{x_{1}}, m_{x_{2}}=1}^{M_{x}^{2}} \sum_{m_{y_{1}}, m_{y_{2}}=1}^{M_{y}^{2}} \alpha_{m_{x_{1}}}\left(x_{1}\right) \alpha_{m_{x_{2}}}\left(x_{2}\right) \\
\times \beta_{m_{y_{1}}}\left(y_{1}\right) \beta_{m_{y_{2}}}\left(y_{2}\right) \Pi(\omega)_{m_{1}, m_{2}}, \\
\operatorname{RSP}(\omega)=\iint_{0}^{a} \iint_{0}^{b} \operatorname{RSP}\left(x_{1}, y_{1}, x_{2}, y_{2}, \omega\right) d x_{1} d x_{2} d y_{1} d y_{2},
\end{gathered}
$$

in which $\Pi(\omega)_{m_{1}, m_{2}}$ are the components of the radiation matrix, defined by

$$
\Pi(\omega)=\mathbf{S}_{V V} \mathbf{M}(\omega),
$$

and $\mathbf{S}_{V V}$ is defined in (38) and $\mathbf{M}(\omega)$ is evaluated numerically from the following equation:

$$
\begin{aligned}
\mathbf{M}(\omega)= & 8 \frac{\rho_{0}}{c_{0}}\left(\frac{\omega a b}{\pi^{3} m_{x} m_{y}}\right)^{2} \\
& \times \iint_{0}^{\pi / 2}\left\{\frac{\cos \left(\frac{\alpha}{2}\right) \cos \left(\frac{\beta}{2}\right)}{\left[\left(\alpha / m_{x} \pi\right)^{2}-1\right]\left[\left(\beta / m_{y} \pi\right)^{2}-1\right]}\right\}^{2} \\
& \times \sin \theta d \theta d \phi,
\end{aligned}
$$

where $\rho_{0}$ and $c_{0}$ are the density and the speed of sound of the interior fluid, respectively, $\alpha=\left(\omega / c_{0}\right) a \sin \theta \cos \phi, \beta=$ $\left(\omega / c_{0}\right) b \sin \theta \sin \phi$, in which $\phi$ and $\theta$ are the angles of the distance vector in space to the observation point [27].

\section{Structural Vibration and Sound Radiation Results}

The formulation presented in the previous section is used to analyze four different rectangular composite sandwich panels of several sizes and materials properties, as shown in Table 1. Additionally, four isotropic aluminum panels with similar sizes compared to the composite panels, as shown in Table 2, are analyzed using the previous model developed by the author; results are then compared with the composite panels. All the eight panels are considered simply supported in the four boundaries and subjected to turbulent boundary layer excitation or to random noise excitation. The turbulent flow excitation is representative of Mach number 0.8 flight conditions, as described in Table 3 , and the random excitation represents a constant 40 Pascal random noise, that is, a sound pressure level of approximately $120 \mathrm{~dB}$. The first ten natural frequencies obtained for the several panels analyzed are shown in Tables 4 and 5, respectively, for composite and isotropic panels. Cases 1, 2, 3, and 4 of composite panels, as noted in Table 4 , are chosen for validation purposes as in studies $[16,18,20]$, respectively. It is shown that the calculated natural frequencies are in good agreement with the previous studies.

3.1. Composite Panels. The results presented in this section discuss the radiated sound power and the structural displacement levels of the composite sandwich panels studied. Results are shown for frequencies up to $1500 \mathrm{~Hz}$, requiring a minimum number of plate modes which is dependent of the panel size and materials properties, for proper accuracy of the predicted values. Values for the radiated sound power, RSP, and plate displacement power spectral density (PSD), $S_{w w}$, are obtained for two locations $\left(x_{1}, y_{1}\right)=(0.5 a, 0.5 b)$ and $\left(x_{2}, y_{2}\right)=(0.3 a, 0.2 b)$, as well as overall values of these two quantities, and shown in Figures 4 and 5. As referred earlier, four different panels are analyzed, identified as Cases 1 through 4 along the following sections, and two types of excitation are applied: (1) turbulent boundary layer excitation and (2) random noise excitation.

As noted in Figure 4, and similarly to what was observed in previous results and formulation dedicated to the analysis of isotropic panels, it is concluded that the overall RSP values differ from local RSP values, especially for the TBL excitation. It is also observed that turbulent flow can be responsible for exciting a higher number of panel modes compared to random noise, with TBL and random noise providing dissimilar levels of panels' sound radiation. As such, to accurately predict the dynamic behaviour of a panel, one should not consider the pure random noise excitation as representative of the turbulent flow excitation. In the overall RSP results, plates of bigger dimensions are shown to have higher RSP values both for TBL and random excitations, with Case 1 showing higher RSP values than Cases 2, 3, or 4. The same is not noted for the local RSP values, with Case 3 panel showing increased RSP values for both positions 1 and 2 with relation to the overall RSP values. These results emphasize the importance of knowing the measuring 


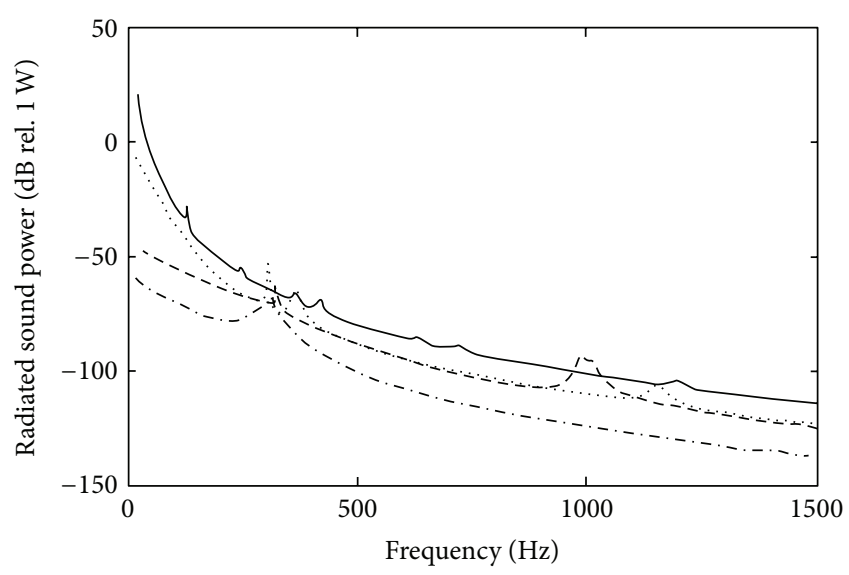

(a)

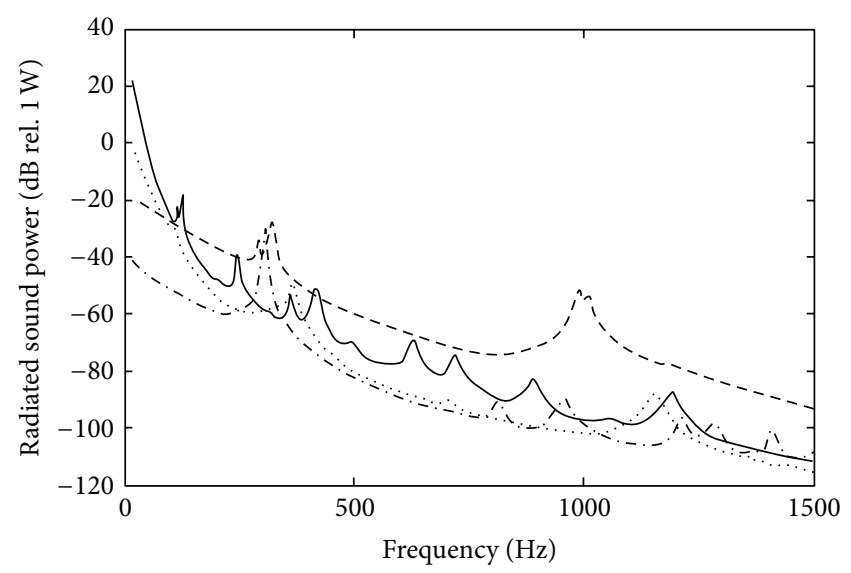

(c)

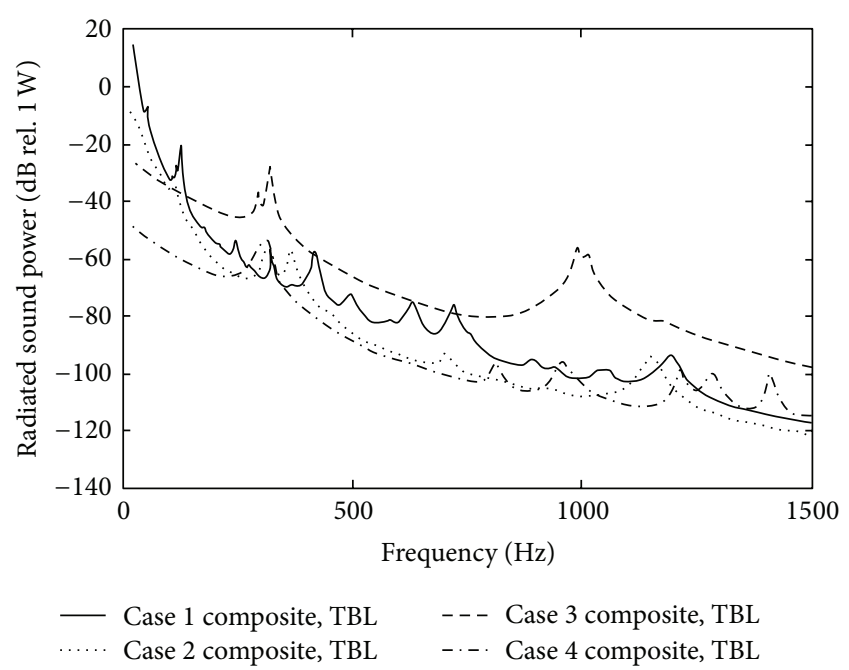

(e)

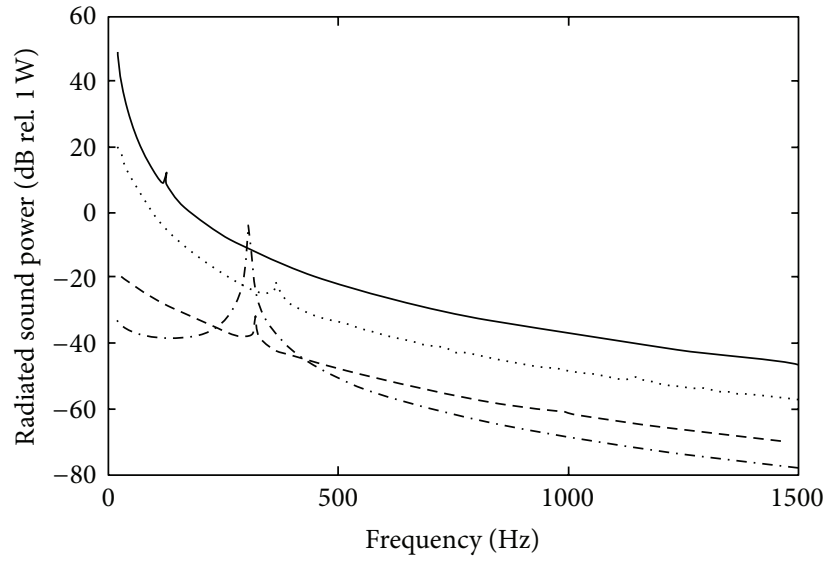

(b)

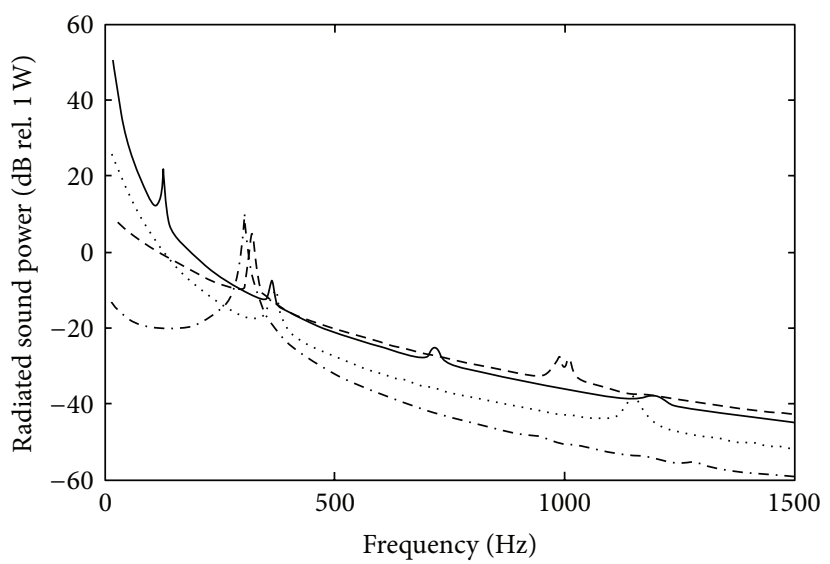

(d)

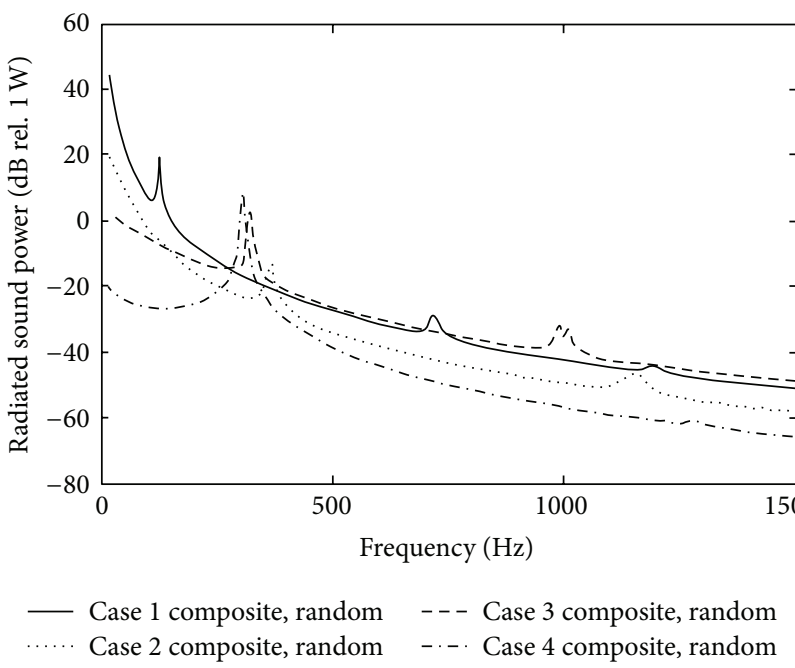

(f)

FIGURE 4: Radiated sound power results for the composite panels: (a) and (b) overall panel RSP; (c) and (d) RSP near surface location $\left(x_{1}, y_{1}\right)=$ $(0.5 a, 0.5 b) ;(\mathrm{e})$ and (f) RSP near location $\left(x_{2}, y_{2}\right)=(0.3 a, 0.2 b)$.

position for the accurate prediction of sound and vibration, and it highlights the desired sensitivity of the developed mathematical framework to this factor. Figure 5 shows the displacement PSD results associated with the same panels and excitations as for the RSP results displayed in Figure 4. Comparing Figures 4 and 5, it is observed that structural displacement and sound radiation levels have different curves for the same excitation, and thus panel displacement PSD 


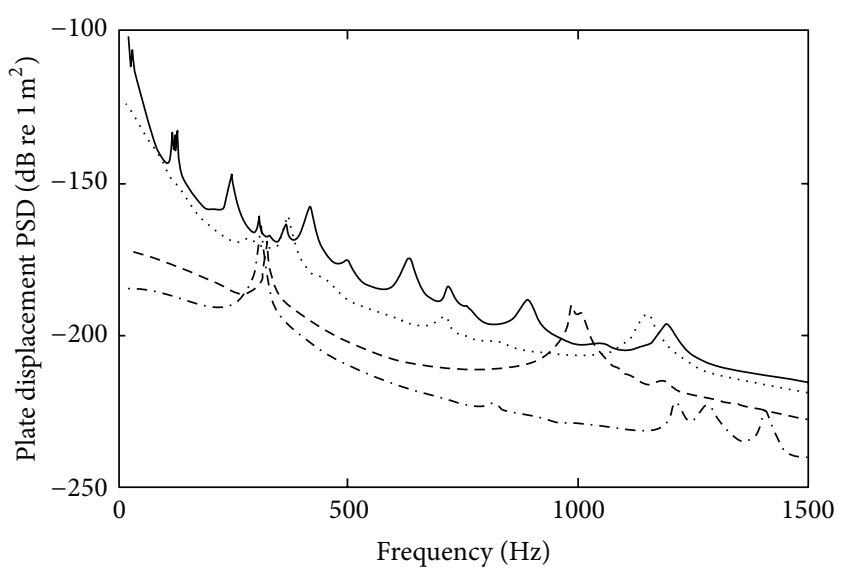

(a)

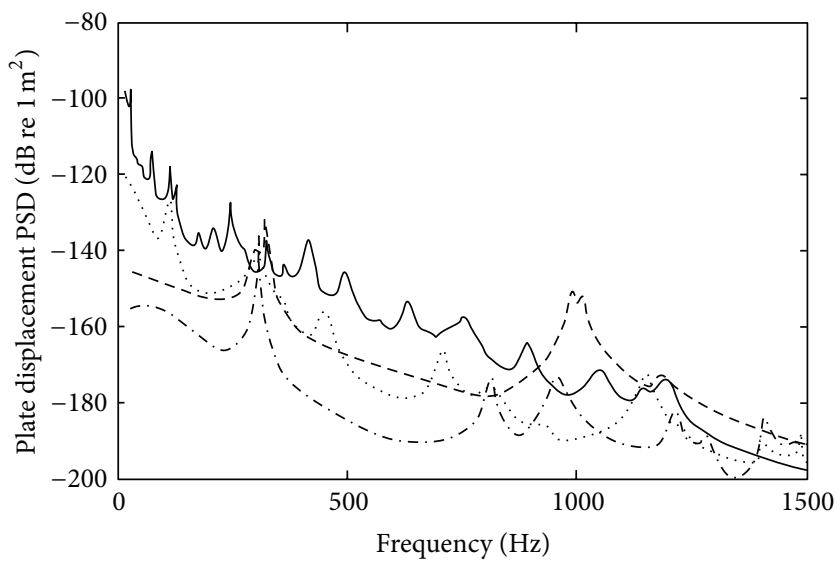

(c)

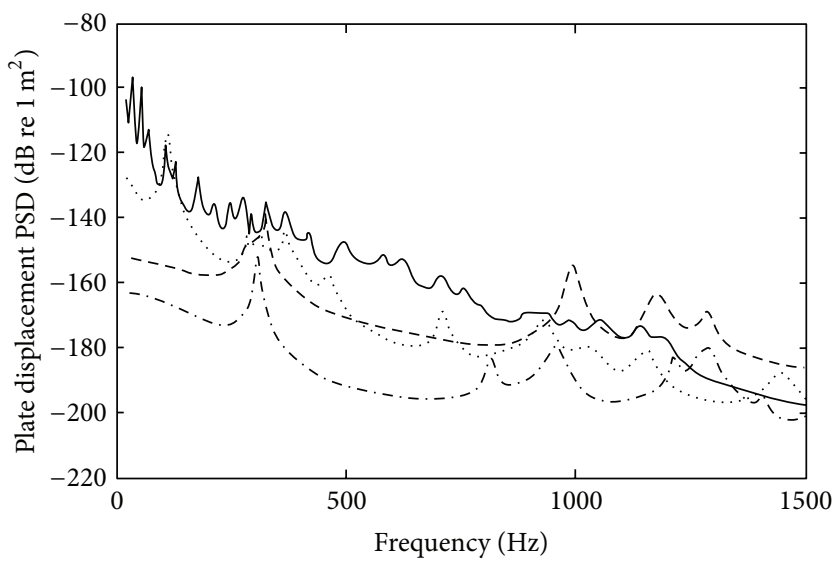

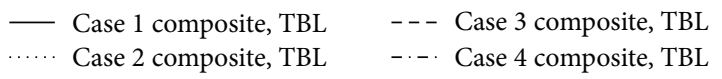

(e)

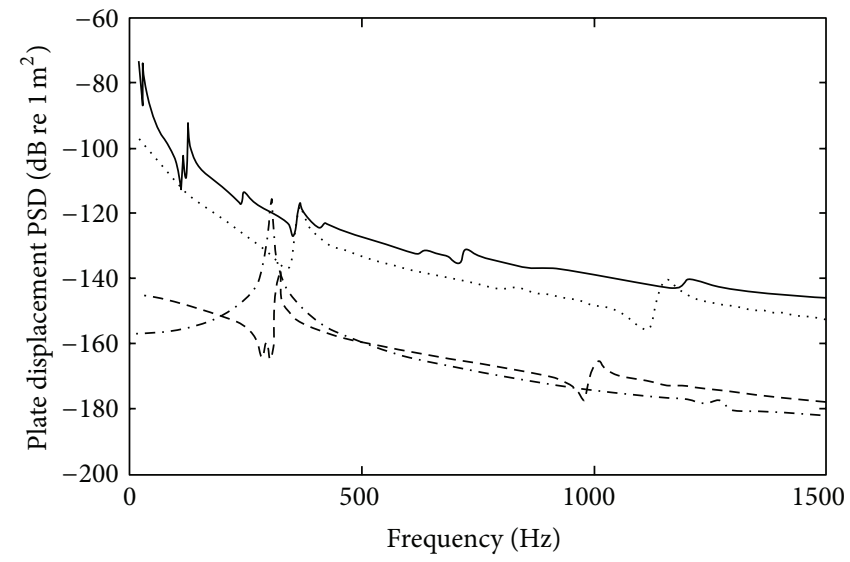

(b)

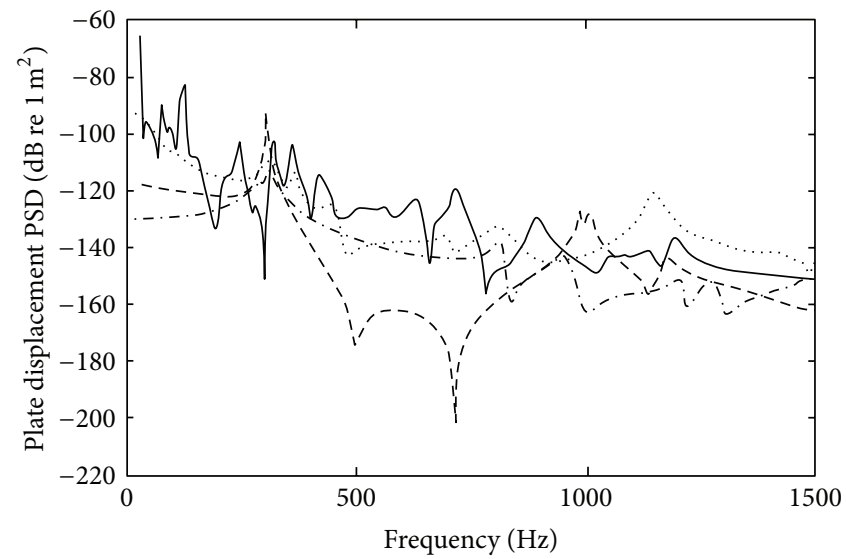

(d)

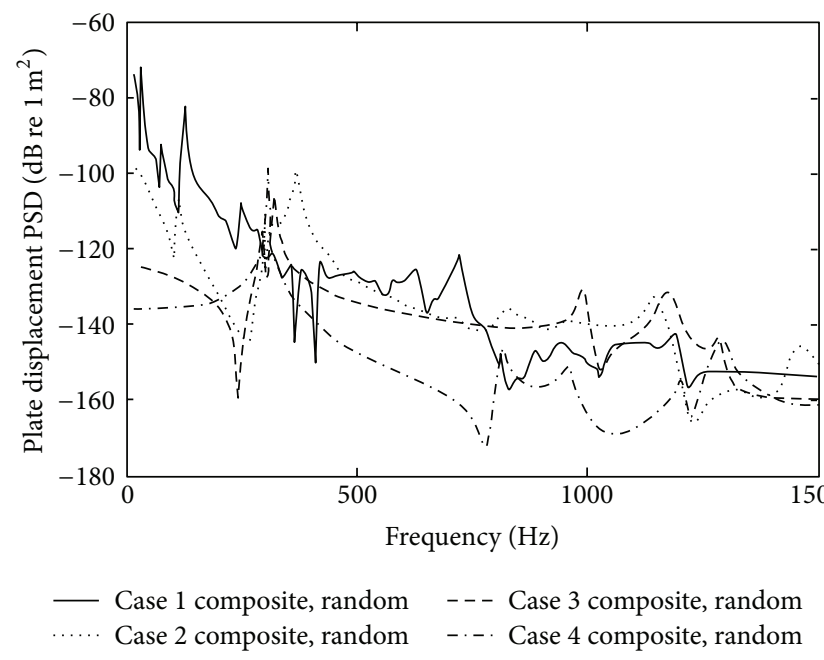

(f)

Figure 5: Panel displacement PSD results for the composite panels: (a) and (b) overall panel $S_{w w}$; (c) and (d) $S_{w w}$ near surface location $\left(x_{1}, y_{1}\right)=(0.5 a, 0.5 b) ;(\mathrm{e})$ and (f) $S_{w w}$ near location $\left(x_{2}, y_{2}\right)=(0.3 a, 0.2 b)$.

curve prediction may not be fully representative of RSP curve, even though they would be expected to follow similar trends. In addition, as similar to RSP results, it is concluded that $S_{w w}$ predictions are dissimilar whether one is assuming TBL or random excitation. Case 1 panel shows higher values of both overall and local plate displacement PSD predictions.

The results presented here are useful in the context of the prediction of noise radiation by composite panel solutions 
and its possible application, for example, in aerospace industry. Based on the obtained results, if one would choose which composite panel solution is most desirable for the purpose of manufacturing an aircraft fuselage panel, a smaller panel (Case 3) or a panel with a higher aspect ratio (Case 4) would be preferable for overall improved results. Longer and wider panels (i.e., Cases 1 and 2) are shown to greatly amplify the low frequency range. However, one would need to design the panel appropriately and with the targeted dimensions, such that the amplification of noise and vibration at certain frequencies would be avoided. For instance, Case 3 panel exhibits a general improved behaviour in terms of noise levels, but simultaneously it amplifies noise at frequencies near $300 \mathrm{~Hz}$ and $1000 \mathrm{~Hz}$, while Case 4 panel amplifies results near $300 \mathrm{~Hz}$. Comparing the size of these two panels, the surface area covered by one Case 1 panel corresponds to approximately the surface area covered by twenty Case 3 panels, with the twenty Case 3 panels representing approximately $9.4 \mathrm{~kg}$ of total mass compared to the $6.76 \mathrm{~kg}$ of a single Case 1 panel. As such, an improvement in the noise levels comes as a tradeoff in terms of increased weight. Additionally, it is shown that panels with thicker face layers and thinner core layer, specifically referring to Cases 3 and 4 , have lower noise and vibration levels than panels with thinner face layers and thicker core layer, referring to Cases 1 and 2. However, as mentioned earlier, Cases 3 and 4 panels, with smaller dimensions and thicker face layers, have the problem of noise amplification at certain frequencies. Therefore, a panel which combines the properties of being shorter with a thicker core layer, versus thinner face layers, may potentially show an improved behaviour for reduced vibration and noise radiation, as well as lower noise amplification at isolated frequencies.

3.2. Isotropic Panels. This section addresses the RSP and $S_{w w}$ predictions for the isotropic panels analyzed, and results up to $1500 \mathrm{~Hz}$ are shown in Figures 6 and 7. Four aluminum isotropic panels are investigated, considering TBL or random excitation, as follows: isotropic panels Cases 3 and 4 have the same dimensions, $a$ and $b$, as the composite panels Cases 3 and 4, respectively; isotropic panels Cases 5 and 6 are considered with same dimensions, $a$ and $b$, as Cases 3 and 4 , respectively, but with increased thicknesses. This approach is taken with the purpose of posterior comparison between composite and isotropic panels' behaviours. In this context, isotropic panels Cases 3 and 4 are both $1 \mathrm{~mm}$ thick, while isotropic panels Cases 4 and 5 have thicknesses of $1.5 \mathrm{~mm}$ and $4 \mathrm{~mm}$, respectively.

As noted in Figures 6 and 7, the increase of panel thickness results in an expected shift in the panel natural frequencies to higher frequencies, as well as a shift in the modes amplified, in both RSP and $S_{w w}$ results. This effect is observed in the TBL and random excitations. Furthermore, it is found that panels with higher aspect ratio (i.e., Cases 4 and 6) are generally characterized by having lower levels of sound radiation and vibration. As similarly noted for the composite panels, random and TBL excitations provide different RSP and $S_{w w}$ predictions, and overall values differ from point values, and hence it is important to specify the location in the panel where the measurements/predictions are being taken. It is also noted that the random excitation remains as the excitation causing higher noise and vibration levels, for all cases, at the higher frequency range. This is also an expected effect, as the TBL excitation decreases towards the higher frequencies, while the random excitation provides a constant excitation over the frequency spectrum.

3.3. Composite versus Isotropic Panels. As one of the main objectives of this study, this section presents a discussion of results for the behavior of composite sandwich panels in comparison with the traditional isotropic panels. The following four figures are shown to this end: Figures 8 and 9 compare results for composite panel Case 3 with isotropic panels Cases 3 and 5, while Figures 10 and 11 compare composite panel Case 4 with isotropic panels Cases 4 and 6 .

By comparing Cases 3 and 5 panels, as shown from Figures 8 and 9, it is noted that composite panel Case 3 exhibits an enhanced behaviour in comparison with isotropic panels Cases 3 and 5, both in RSP and displacement PSD levels. However, one should also note that Case 3 composite panel shows higher levels of noise and vibration at specific isolated frequencies, approximately near $300 \mathrm{~Hz}$ and $1000 \mathrm{~Hz}$, for the overall RSP and for position 1 RSP results, as shown in Figure 8. Considering the panel displacement PSD results, in Figure 9, extra frequencies above $1000 \mathrm{~Hz}$ are also amplified, especially at position 2, for both TBL and random excitations. As described in Table 1, the composite panel Case 3 has a thin core layer; thus, the unwanted amplification at these frequencies may be attenuated by increasing the core layer thickness. However, this modification on the panel thickness will increase the original panel weight of $0.47 \mathrm{~kg}$, which already represents heavier solution compared to Cases 3 and 5 isotropic panels, with weights of $0.3 \mathrm{~kg}$ and $0.45 \mathrm{~kg}$, respectively. Although the panel weight will increase if this change is performed, making this modification will in a later phase require less added acoustic insulation material to the aircraft walls, in the context of aircraft fuselage panels' application. As such, the composite panel may represent, with a slight increase in the panel weight, an optimized solution for both sound radiation and structural vibration in almost all the frequency spectra analyzed.

Similar conclusions are obtained from Figures 10 and 11, dedicated to the comparison of Cases 4 and 6 panels; that is, the composite panel represents an improved solution for almost all the frequency ranges studied. By analyzing the geometric differences between composite panels Cases 3 and 4 , Case 4 has thicker face layers and is longer than Case 3 panel, having a much higher aspect ratio. The amplification of noise and vibration levels at specific frequencies is noted, as in Case 3 composite panel. Since face layers are thicker and this panel has a higher aspect ratio, this effect is more visible in composite Case 4 than in composite Case 3. As observed in results from Case 3, this could be enhanced by implementing an increase of the core layer thickness. While the increase in the face layer thickness is shown to decrease the levels of noise and vibration in both overall and localized predictions, it also can have an impact in the 


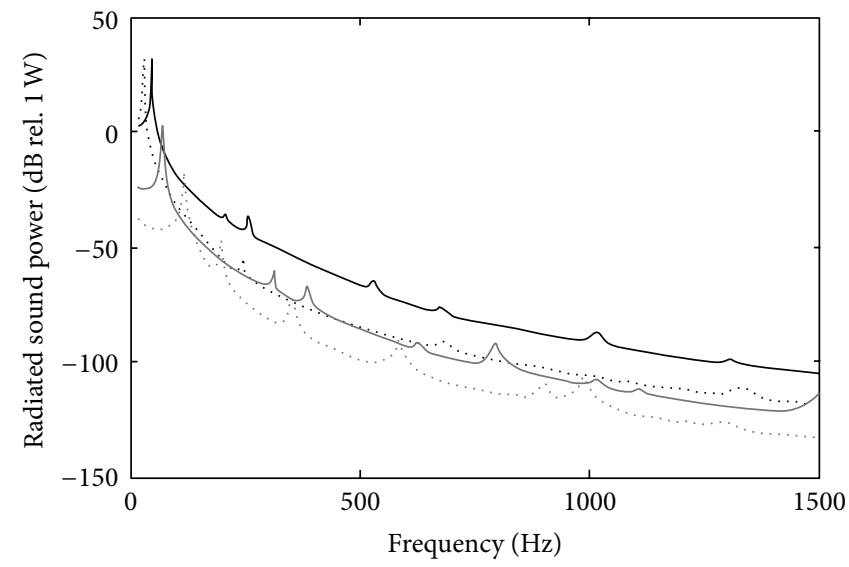

(a)

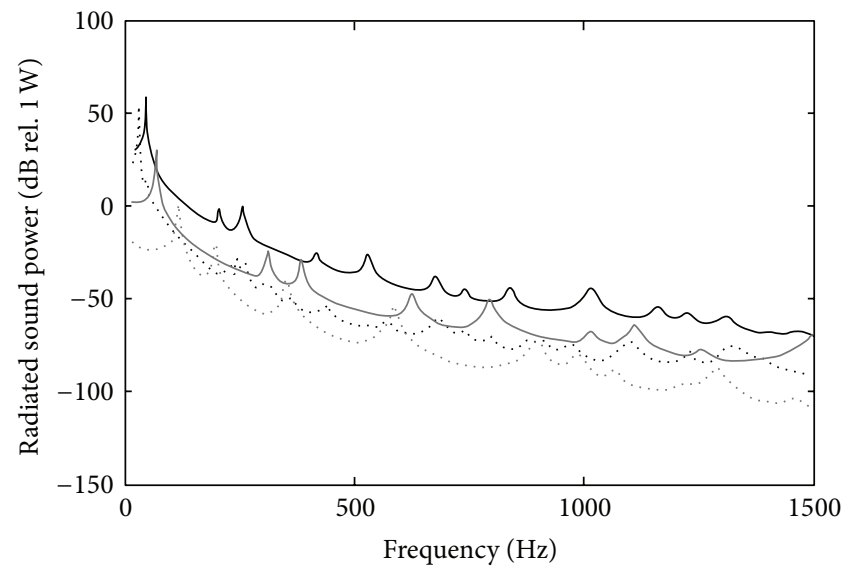

(c)

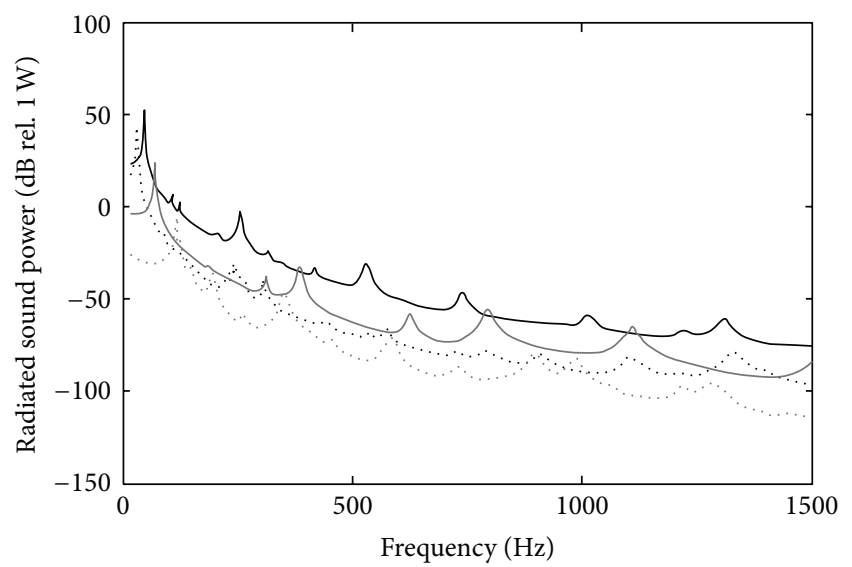

$\begin{array}{lll}- & \text { Case } 3 \text { isotropic, TBL } & \text { Case } 5 \text { isotropic, TBL } \\ \cdots & \text { Case } 4 \text { isotropic, TBL } & \text { C.... Case } 6 \text { isotropic, TBL }\end{array}$

(e)

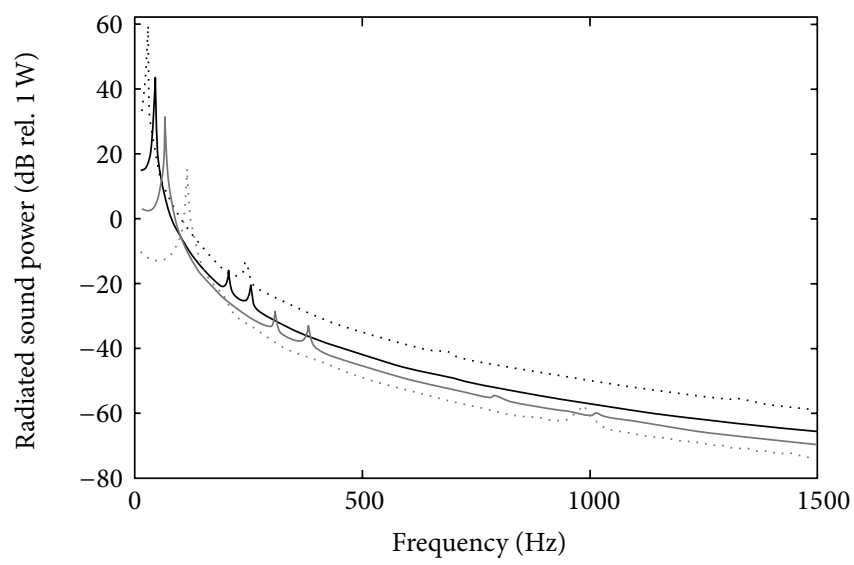

(b)

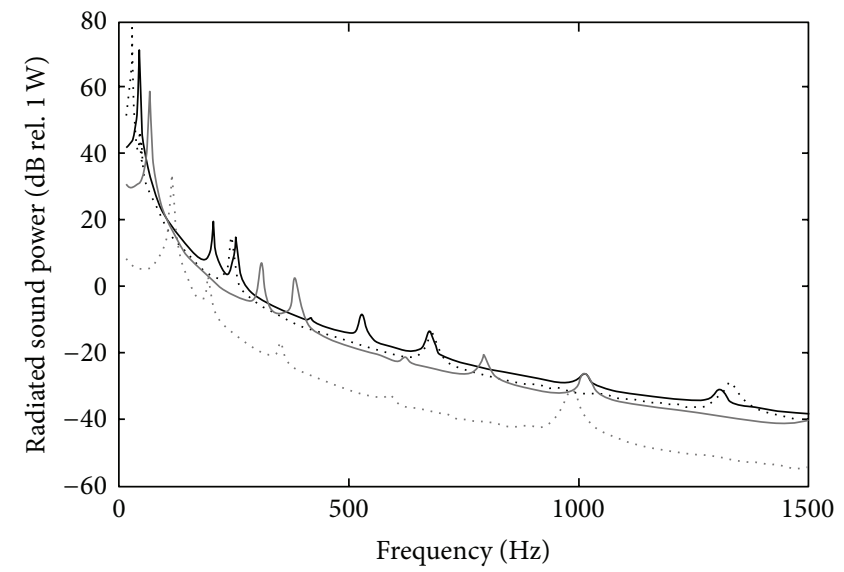

(d)

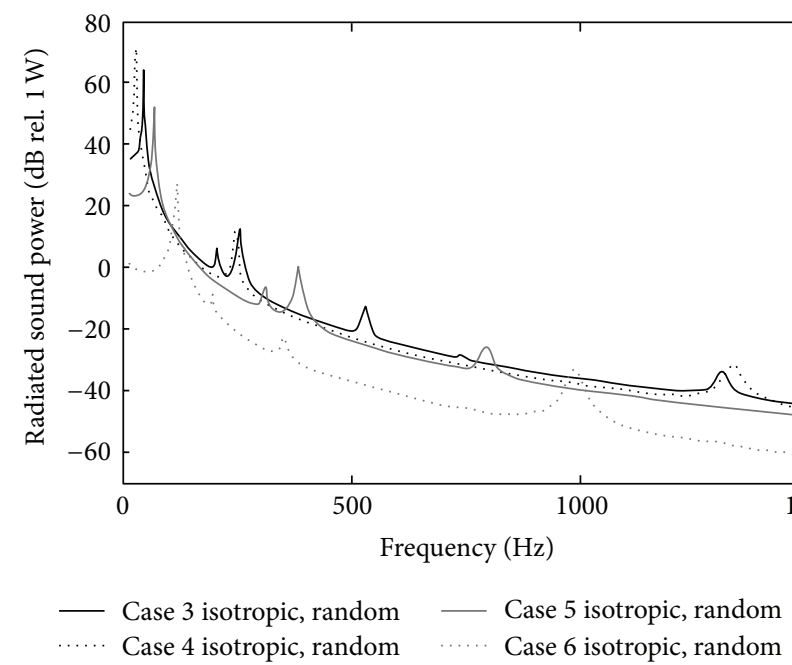

(f)

FIGURE 6: Radiated sound power results for the isotropic panels: (a) and (b) overall panel RSP; (c) and (d) RSP near surface location $\left(x_{1}, y_{1}\right)=$ $(0.5 a, 0.5 b)$; (e) and (f) RSP near location $\left(x_{2}, y_{2}\right)=(0.3 a, 0.2 b)$. 


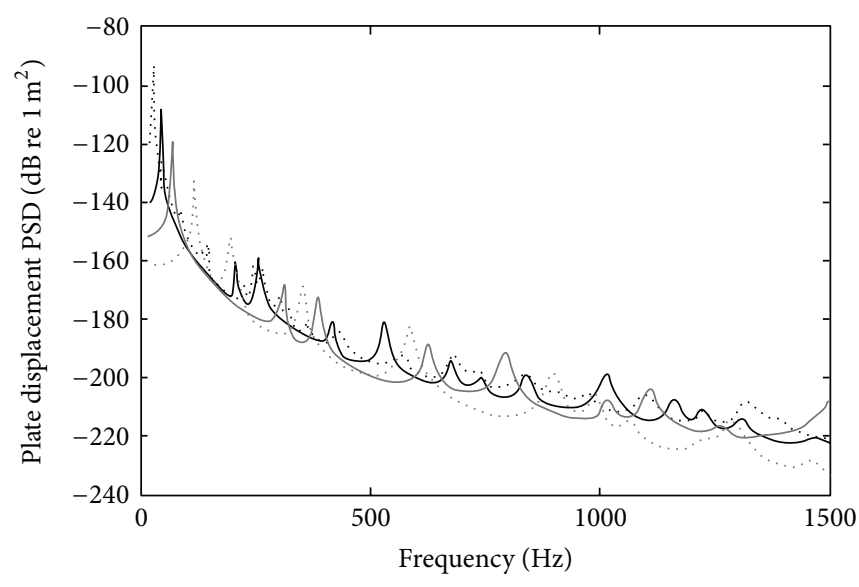

(a)

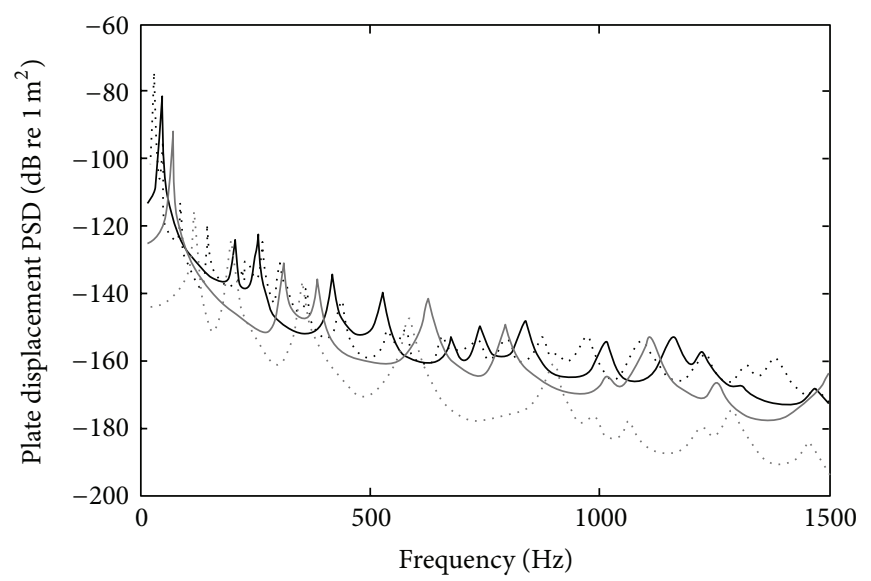

(c)

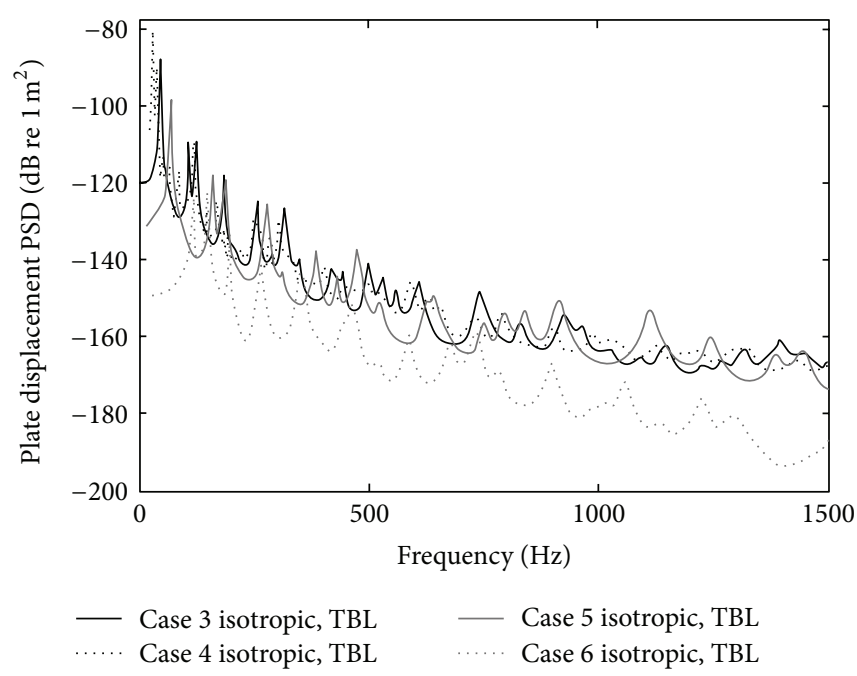

(e)

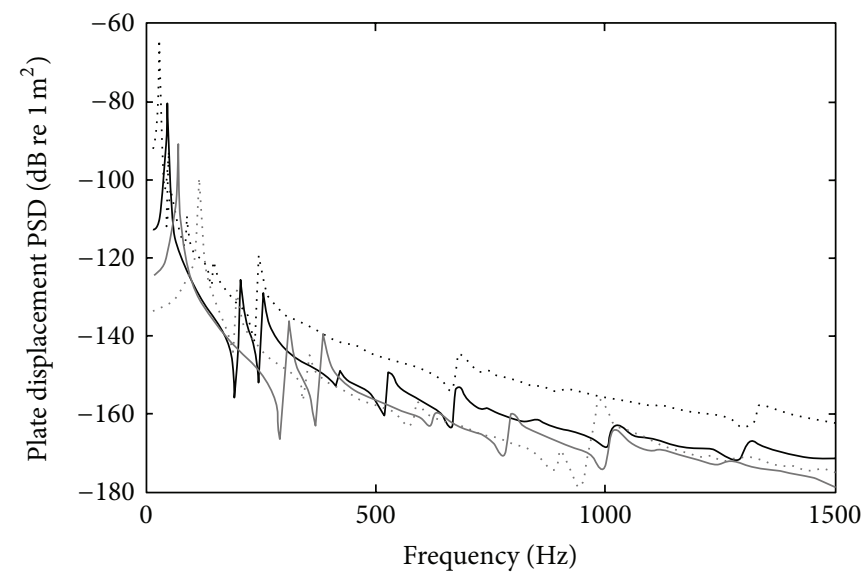

(b)

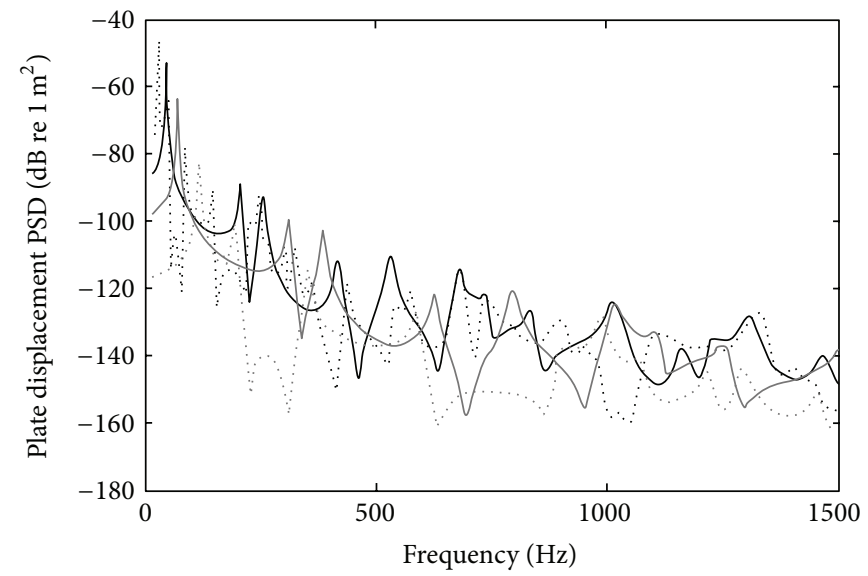

(d)

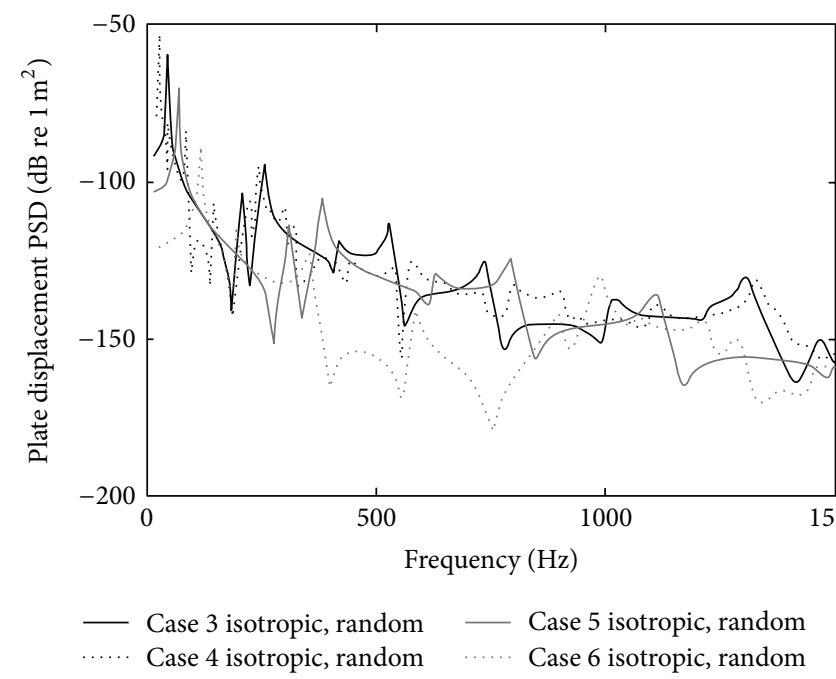

(f)

FIGURE 7: Panel displacement PSD results for the isotropic panels: (a) and (b) overall panel $S_{w w}$; (c) and (d) $S_{w w}$ near surface location $\left(x_{1}, y_{1}\right)=$ $(0.5 a, 0.5 b)$; (e) and (f) $S_{w w}$ near location $\left(x_{2}, y_{2}\right)=(0.3 a, 0.2 b)$. 


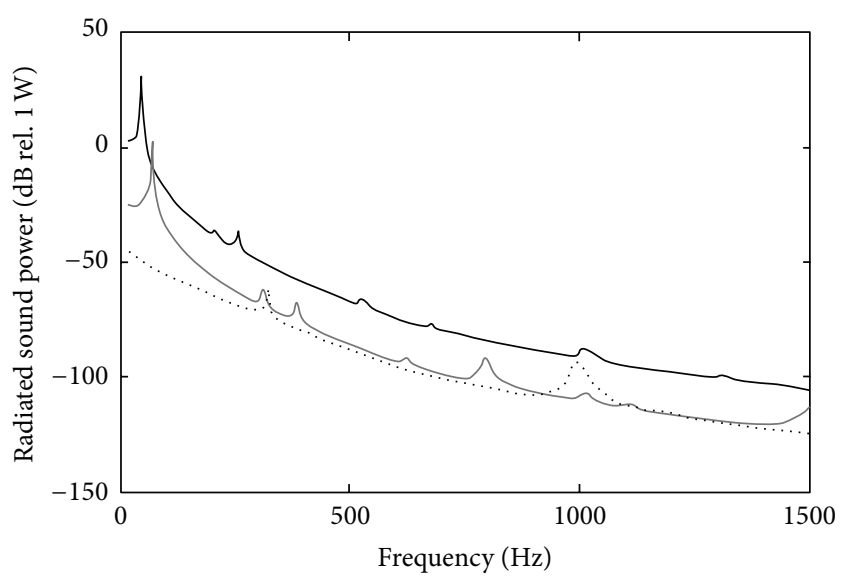

(a)

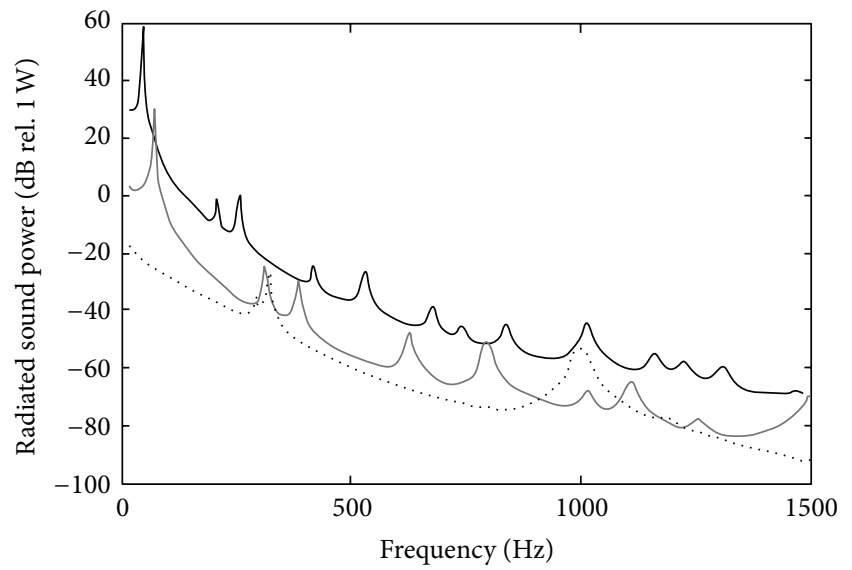

(c)

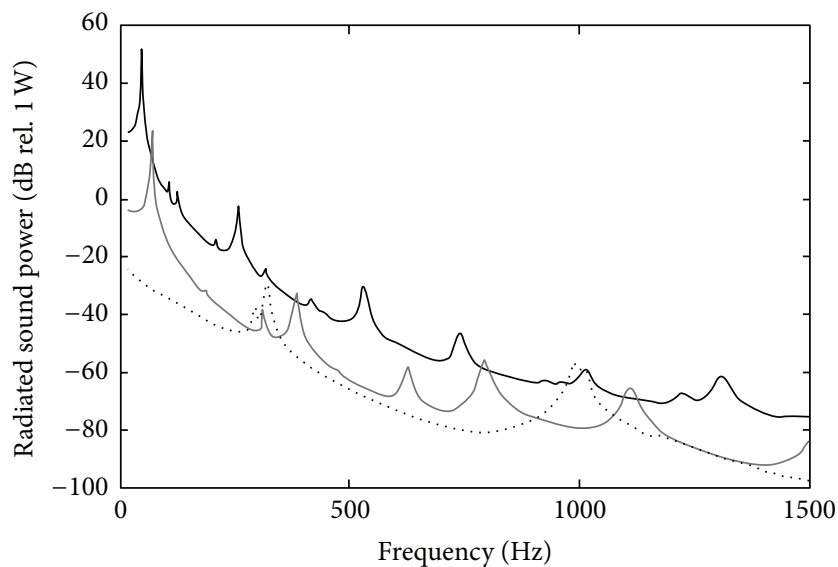

- Case 3 isotropic, TBL Case 3 composite, TBL

_ Case 5 isotropic, TBL

(e)

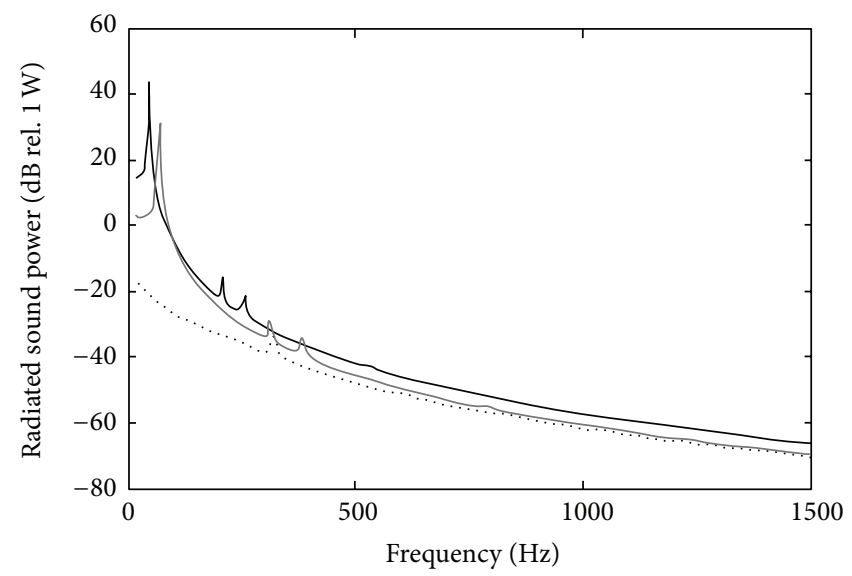

(b)

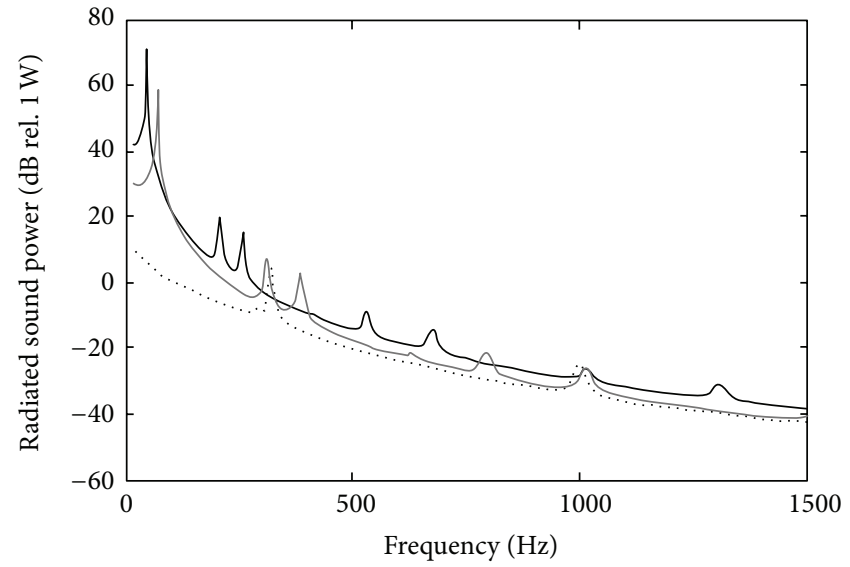

(d)

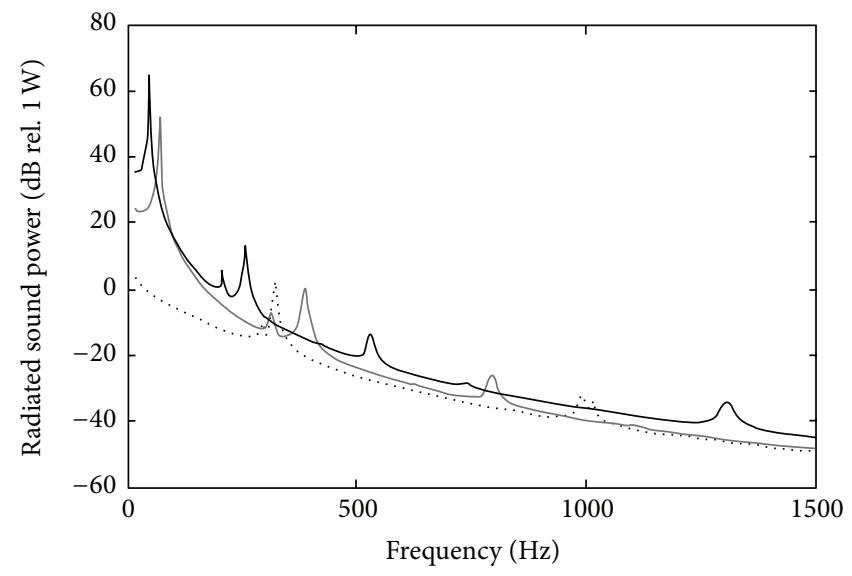

- Case 3 isotropic, random — Case 5 isotropic, random Case 3 composite, random

(f)

FIGURE 8: Comparison of radiated sound power results, for Case 3 composite panel versus Cases 3 and 5 isotropic panels: (a) and (b) overall panel RSP; (c) and (d) RSP near surface location $\left(x_{1}, y_{1}\right)=(0.5 a, 0.5 b)$; (e) and (f) RSP near location $\left(x_{2}, y_{2}\right)=(0.3 a, 0.2 b)$. 


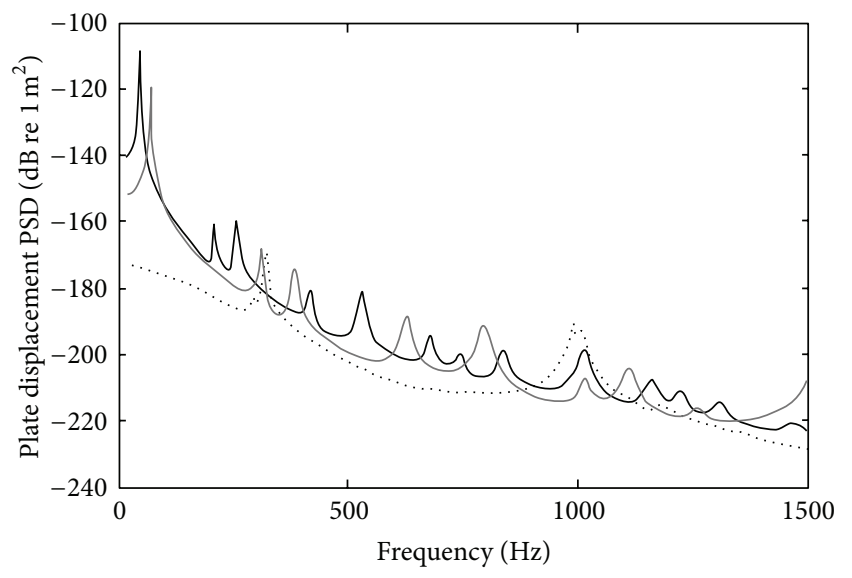

(a)

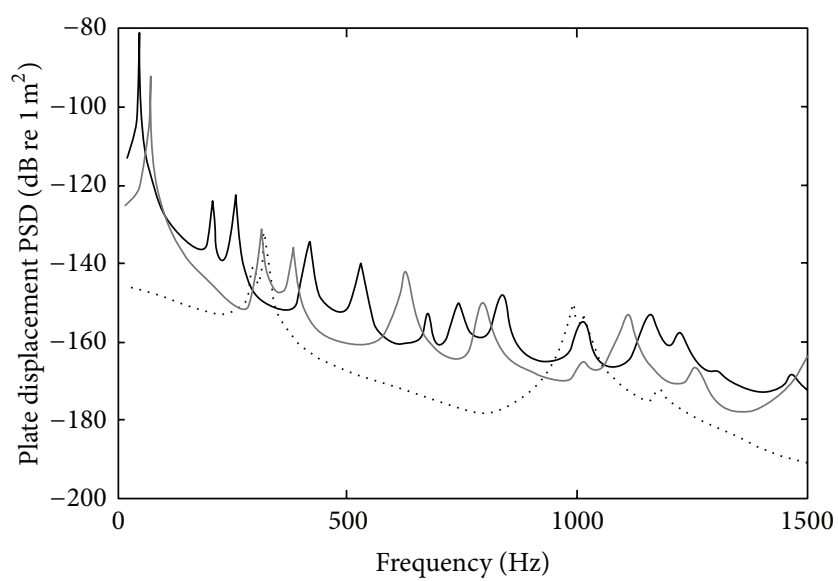

(c)

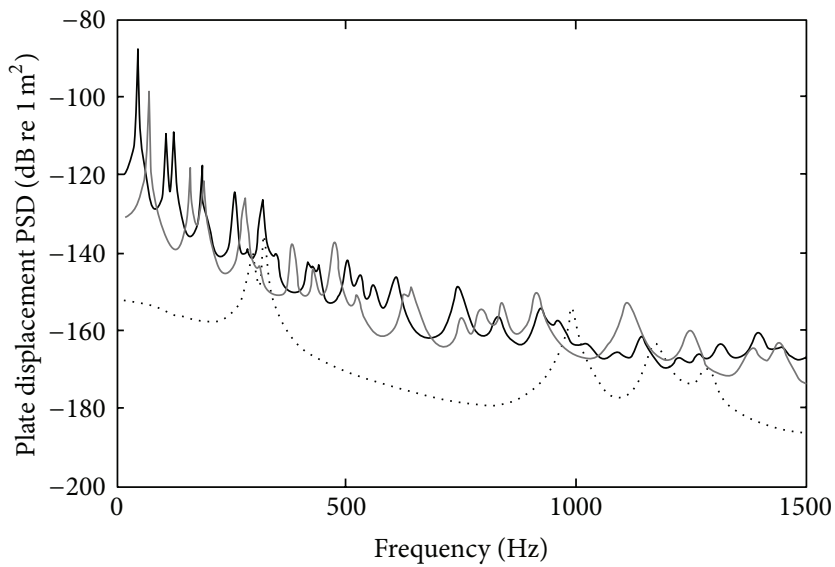

- Case 3 isotropic, TBL Case 3 composite, TBL

(e)

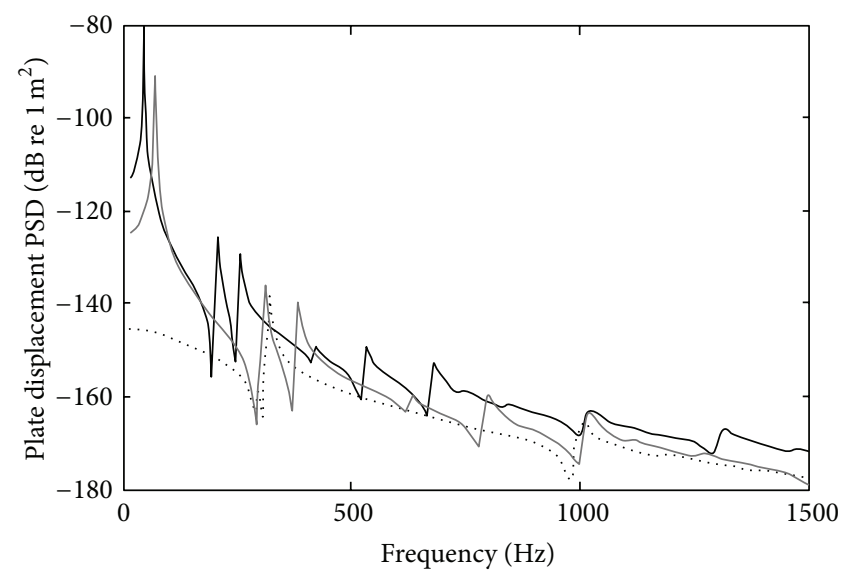

(b)

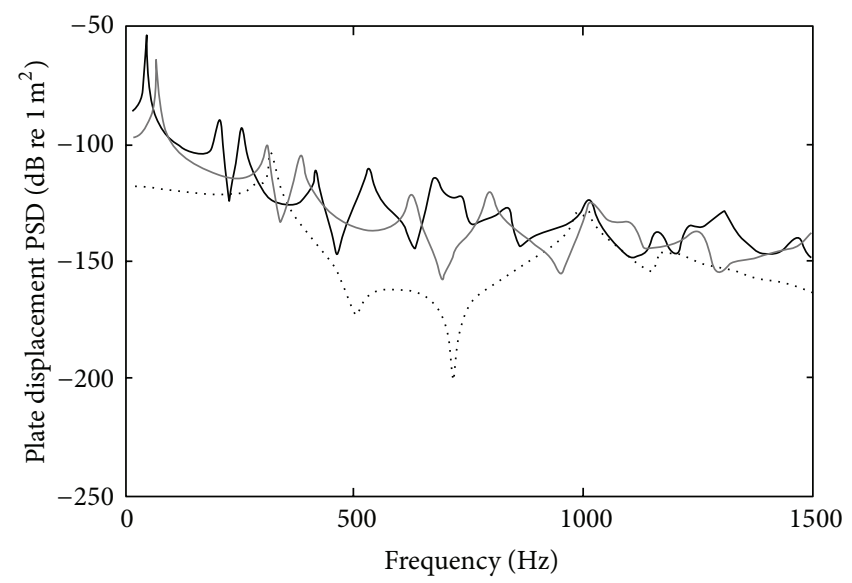

(d)

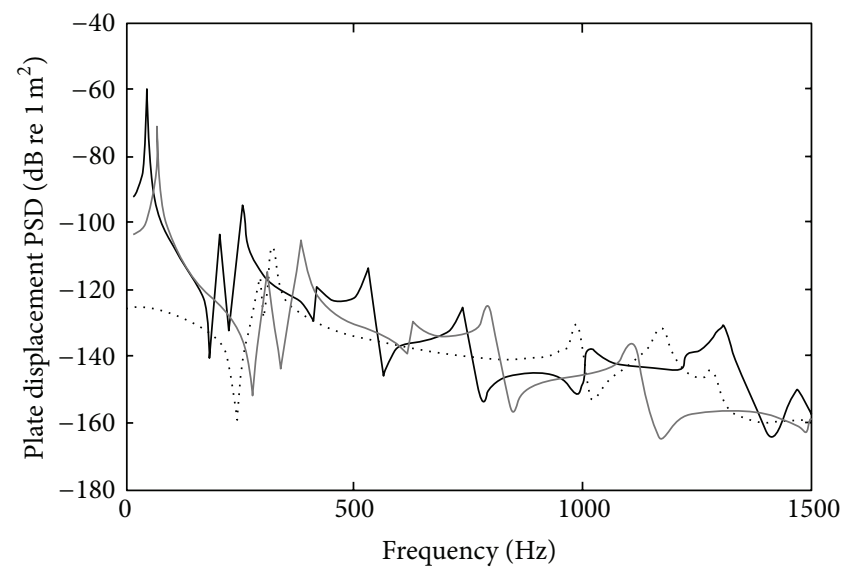

- Case 3 isotropic, random —.. Case 5 isotropic, random
composite, random (f)

Figure 9: Comparison of panel displacement PSD results, for Case 3 composite panel versus Cases 3 and 5 isotropic panels: (a) and (b) overall panel $S_{w w} ;(\mathrm{c})$ and (d) $S_{w w}$ near surface location $\left(x_{1}, y_{1}\right)=(0.5 a, 0.5 b)$; (e) and (f) $S_{w w}$ near location $\left(x_{2}, y_{2}\right)=(0.3 a, 0.2 b)$. 


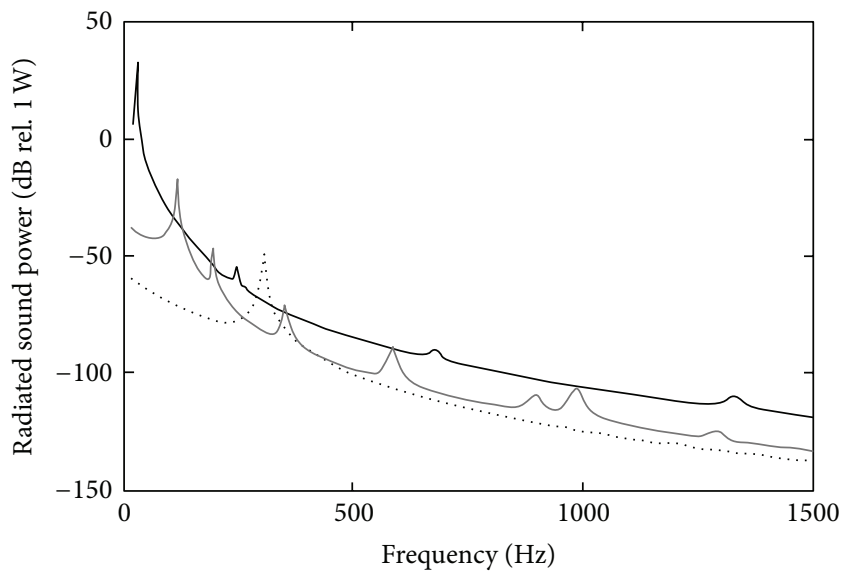

(a)

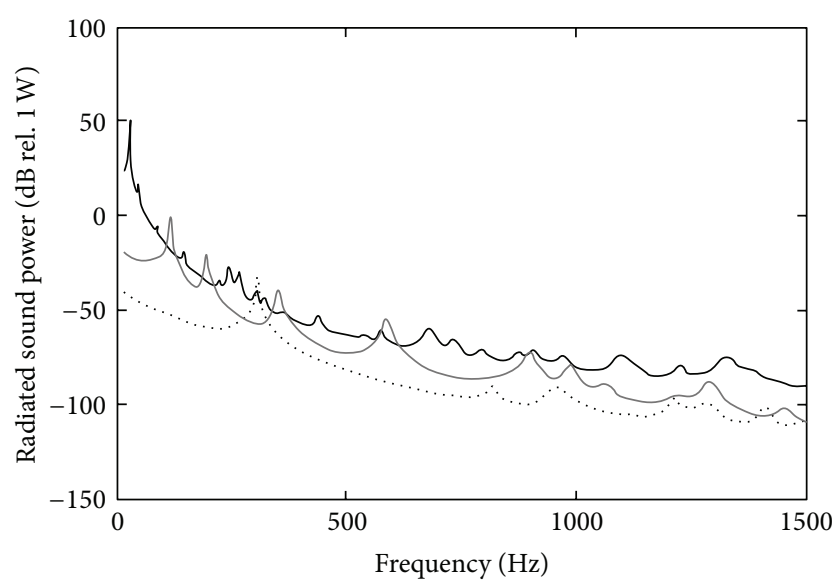

(c)

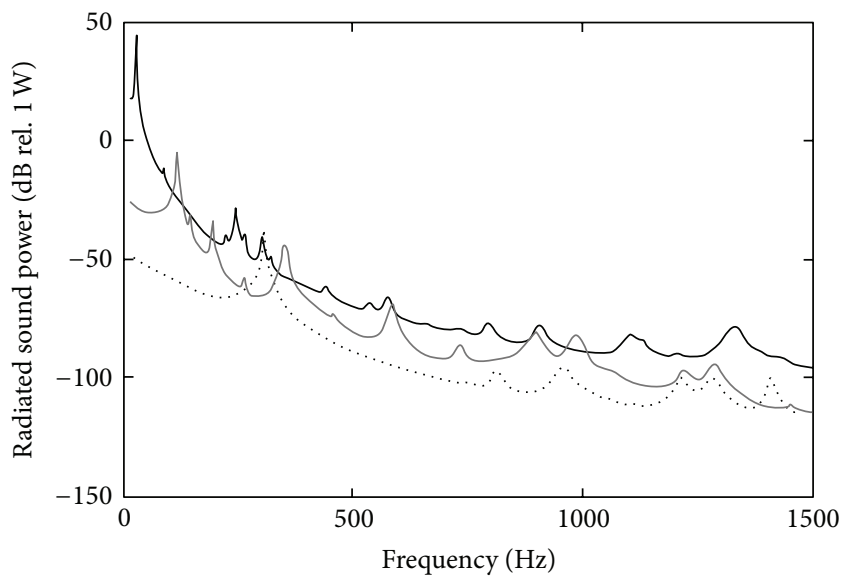

- Case 4 isotropic, TBL Case 4 composite, TBL

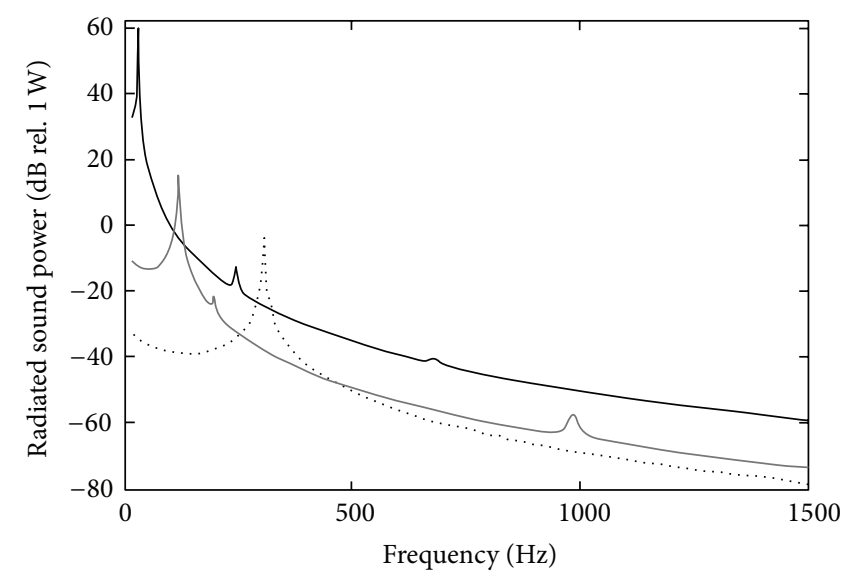

(b)

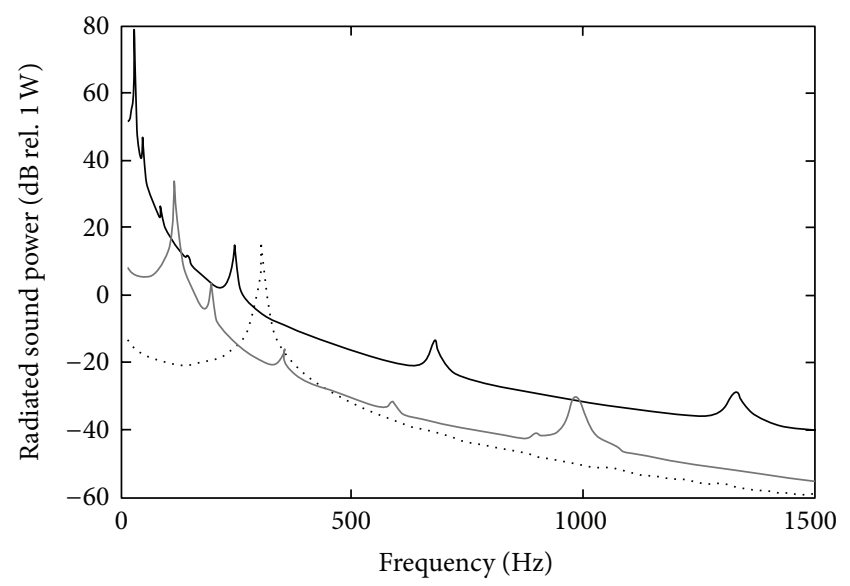

(d)

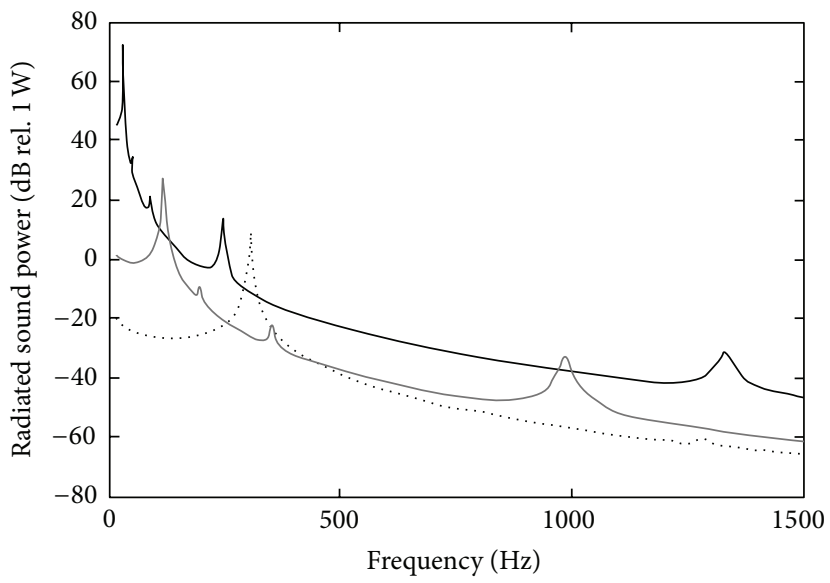

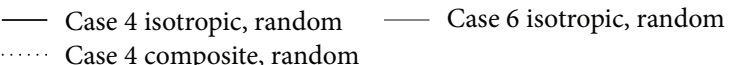

(f)

Figure 10: Comparison of radiated sound power results, for Case 4 composite panel versus Cases 4 and 6 isotropic panels: (a) and (b) overall panel RSP; (c) and (d) RSP near surface location $\left(x_{1}, y_{1}\right)=(0.5 a, 0.5 b)$; (e) and (f) RSP near location $\left(x_{2}, y_{2}\right)=(0.3 a, 0.2 b)$. 


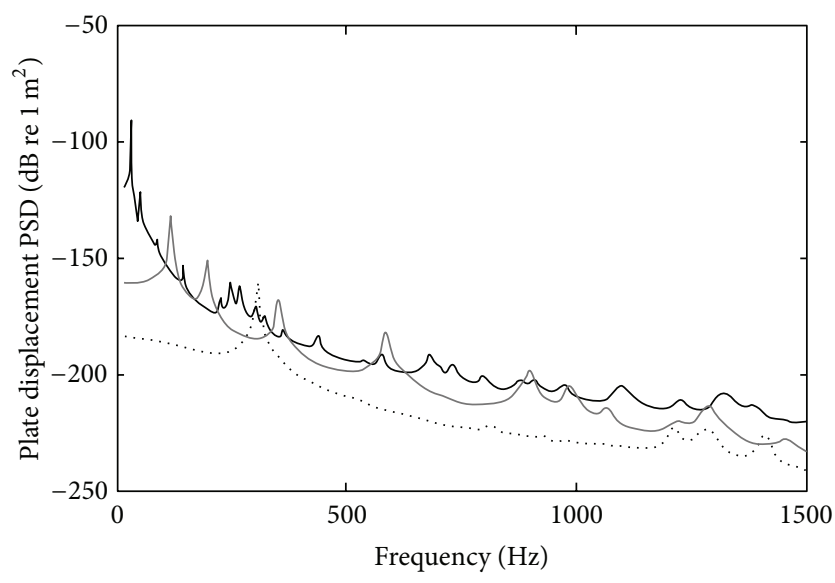

(a)

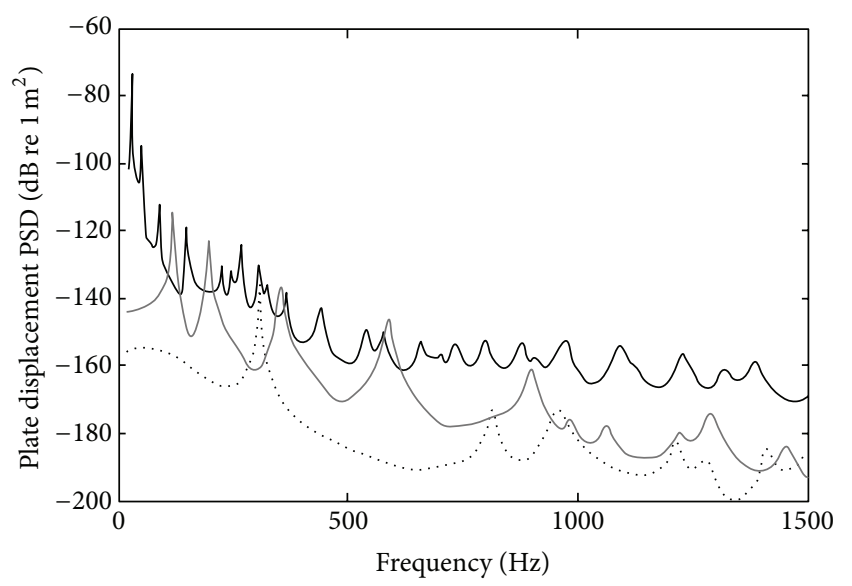

(c)

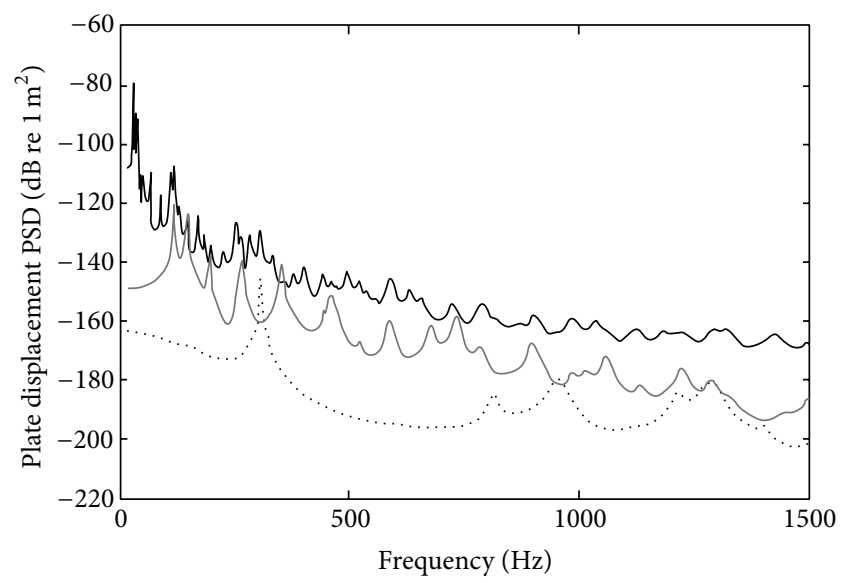

- Case 4 isotropic, TBL … Case 4 composite, TBL

(e)

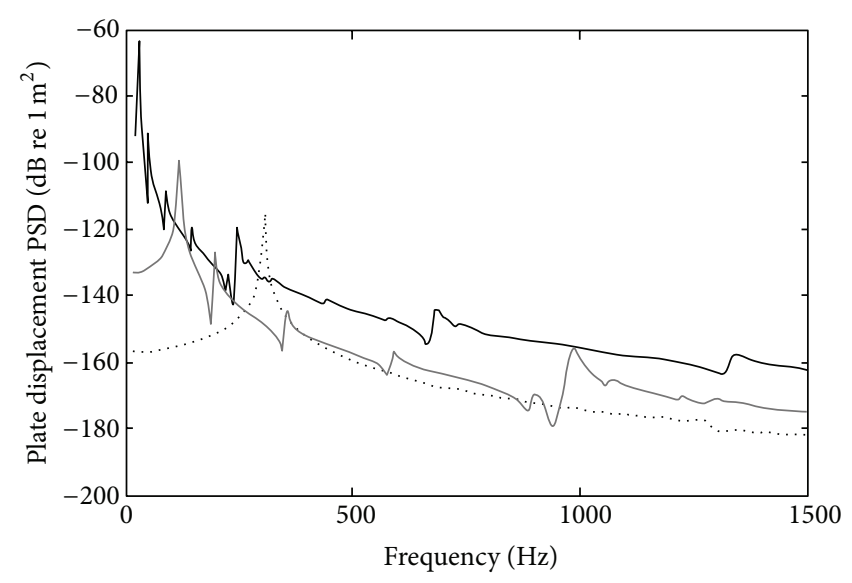

(b)

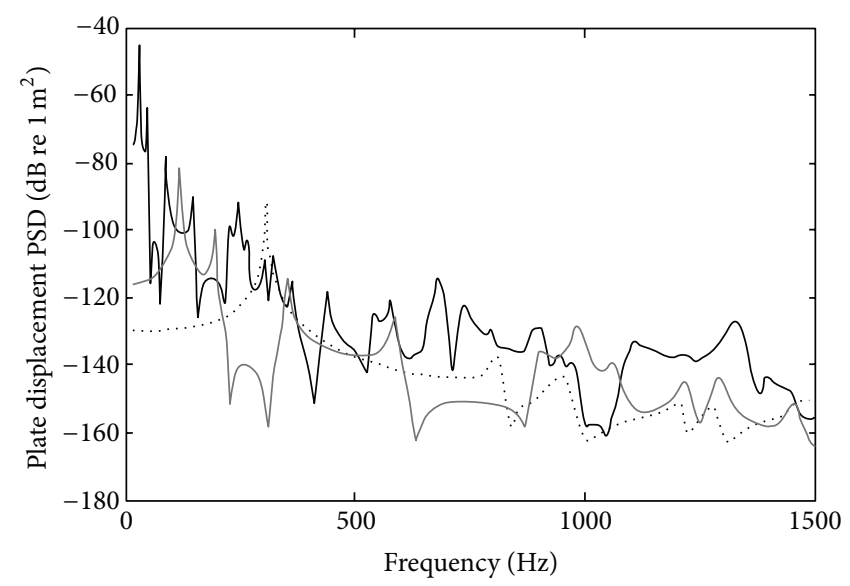

(d)

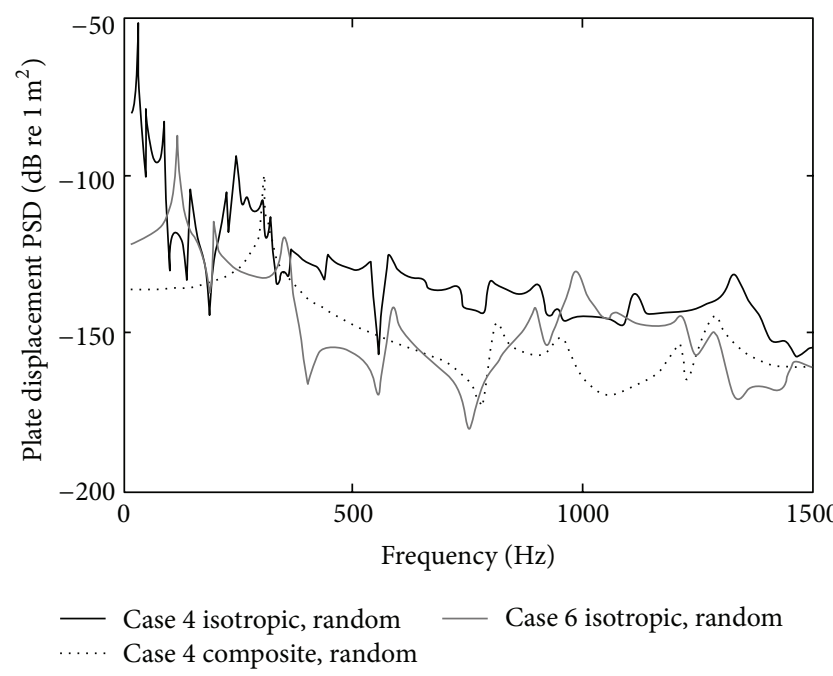

(f)

FIGURE 11: Comparison of panel displacement PSD results, for Case 4 composite panel versus Cases 4 and 6 isotropic panels: (a) and (b) overall panel $S_{w w}$; (c) and (d) $S_{w w}$ near surface location $\left(x_{1}, y_{1}\right)=(0.5 a, 0.5 b)$; (e) and (f) $S_{w w}$ near location $\left(x_{2}, y_{2}\right)=(0.3 a, 0.2 b)$. 
TABLE 1: Physical properties of composite panels.

\begin{tabular}{|c|c|c|c|c|c|}
\hline Variable & Description, units & Case 1 & Case 2 & Case 3 & Case 4 \\
\hline$a$ & Length, $\mathrm{m}$ & 1.83 & 1.1683 & 0.348 & 1.0 \\
\hline$b$ & Width, m & 1.22 & 1.1683 & 0.3048 & 0.3 \\
\hline$\lambda$ & Aspect ratio $(a / b)$ & 1.5 & 1.0 & 1.14 & 3.33 \\
\hline$h_{1}, h_{3}$ & Face layers thickness, $\mathrm{mm}$ & 0.406 & 0.506 & 0.762 & 3.5 \\
\hline$h_{2}$ & Core layer thickness, mm & 6.4 & 19.05 & 0.254 & 0.5 \\
\hline$E_{1}, E_{3}$ & Face layers Young modulus, $\mathrm{Pa}$ & $6.898 \times 10^{10}$ & $7.1 \times 10^{10}$ & $6.898 \times 10^{10}$ & $6.6 \times 10^{10}$ \\
\hline$E_{2}$ & Core layer Young modulus, $\mathrm{Pa}$ & $4.57 \times 10^{5}$ & $4.57 \times 10^{5}$ & $2.67 \times 10^{6}$ & $2.6 \times 10^{8}$ \\
\hline$v_{1}, v_{3}$ & Face layers Poisson's ratio & 0.33 & 0.33 & 0.3 & 0.33 \\
\hline$v_{2}$ & Core layer Poisson's ratio & 0.4 & 0.4 & 0.49 & 0.3 \\
\hline$\rho_{1}, \rho_{3}$ & Face layers density, $\mathrm{kg} \mathrm{m}^{-3}$ & 2768 & 2700 & 2740 & 2680 \\
\hline$\rho_{2}$ & Core layer density, $\mathrm{kg} \mathrm{m}^{-3}$ & 122 & 48.06 & 999 & 1680 \\
\hline$m$ & Total mass, kg & 6.76 & 4.99 & 0.47 & 5.88 \\
\hline
\end{tabular}

TABLE 2: Physical properties of isotropic panels.

\begin{tabular}{|c|c|c|c|c|c|}
\hline Variable & Description, units & Case 3 & Case 4 & Case 5 & Case 6 \\
\hline $\bar{a}$ & Length, $\mathrm{m}$ & 0.348 & 1.0 & 0.348 & 1.0 \\
\hline$b$ & Width, m & 0.3048 & 0.3 & 0.3048 & 0.3 \\
\hline$\lambda$ & Aspect ratio $(a / b)$ & 1.14 & 3.33 & 1.14 & 3.33 \\
\hline$h_{p}$ & Thickness, mm & 1 & 1 & 1.5 & 4 \\
\hline$E_{p}$ & Young modulus, $\mathrm{Pa}$ & $7.24 \times 10^{10}$ & $7.24 \times 10^{10}$ & $7.24 \times 10^{10}$ & $7.24 \times 10^{10}$ \\
\hline$v_{p}$ & Poisson's ratio & 0.33 & 0.33 & 0.33 & 0.33 \\
\hline$\rho_{p}$ & Density, $\mathrm{kg} \mathrm{m}^{-3}$ & 2800 & 2800 & 2800 & 2800 \\
\hline$m$ & Total mass, $\mathrm{kg}$ & 0.30 & 0.84 & 0.45 & 3.36 \\
\hline
\end{tabular}

TABLE 3: Flight test conditions and air properties.

\begin{tabular}{lcc}
\hline Variable & Description, units & Value \\
\hline$M$ & Mach number & 0.8 \\
alt & Altitude, $\mathrm{m}$ & 13106 \\
$c$ & Speed of sound, $\mathrm{m} \mathrm{s}^{-1}$ & 295 \\
$U_{\infty}$ & Flow speed, $\mathrm{m} \mathrm{s}^{-1}$ & 236.06 \\
$\rho$ & Air density, $\mathrm{kg} \mathrm{m}^{-3}$ & 0.2622 \\
$v$ & Kinematic viscosity, $\mathrm{m} \mathrm{s}^{2}$ & $5.422 \times 10^{-5}$ \\
$T$ & Temperature, $\mathrm{K}$ & 216.65 \\
$\operatorname{Re}_{x}$ & Reynolds number & $2.917 \times 10^{7}$ \\
$c_{0}$ & Speed of sound, $\mathrm{m} \mathrm{s}^{-1}$ & 340 \\
$\rho_{0}$ & Internal air density, $\mathrm{kg} \mathrm{m}^{-3}$ & 1.42 \\
\hline
\end{tabular}

higher amplification of localized frequencies. Therefore, the face layers thickness increase should be performed carefully, by an accompanied increase in the core layer thickness, while simultaneously considering the weight constraints for the specific panels applications.

A more detailed analysis will be required in order to formulate final conclusions about the optimum solutions for the panel in the context of aircraft application. For that, the insulation materials would also be considered to account for the respective added weight and effect in the sound radiation signature. However, typically the acoustic insulation materials will only have a higher impact in decreasing the
TABLE 4: First 10 natural frequencies for the composite panels.

\begin{tabular}{lcccc}
\hline Modes & $\begin{array}{c}f, \mathrm{~Hz} \\
(\text { Case 1) }\end{array}$ & $\begin{array}{c}f, \mathrm{~Hz} \\
(\text { Case 2) }\end{array}$ & $\begin{array}{c}f, \mathrm{~Hz} \\
(\text { Case 3) }\end{array}$ & $\begin{array}{c}f, \mathrm{~Hz} \\
(\text { Case 4) }\end{array}$ \\
\hline 1 & 23.65 & 105.88 & 48.74 & 126.58 \\
2 & 45.48 & 264.70 & 112.22 & 157.93 \\
3 & 72.76 & 423.52 & 131.48 & 210.19 \\
4 & 81.86 & 529.41 & 194.96 & 283.35 \\
5 & 94.59 & 688.23 & 218.00 & 377.41 \\
6 & 130.97 & 899.99 & 269.39 & 474.96 \\
7 & 132.79 & 952.93 & 300.75 & 492.38 \\
8 & 154.62 & 1058.81 & 332.87 & 506.32 \\
9 & 176.45 & 1323.51 & 366.12 & 558.57 \\
10 & 181.91 & 1376.45 & 438.66 & 628.25 \\
\hline
\end{tabular}

sound levels at higher frequency ranges, and will therefore not improve significantly the problem of higher noise levels in the low frequency range, particularly observed in the isotropic solutions. As such, the composite panel solutions may appear to be a promising replacement to the isotropic panels, especially panels like Cases 3 and 4, which are already characterized by lower levels of both RSP and $S_{w w}$ in the low frequency range. In further analysis, it will also be important to carefully address the noise amplification at isolated frequencies, by identifying a good combination of 
TABLE 5: First 10 natural frequencies for the isotropic panels.

\begin{tabular}{lcccc}
\hline Modes & $\begin{array}{c}f, \mathrm{~Hz} \\
(\text { Case 3) }\end{array}$ & $\begin{array}{c}f, \mathrm{~Hz} \\
(\text { Case 4) }\end{array}$ & $\begin{array}{c}f, \mathrm{~Hz} \\
(\text { Case 5) }\end{array}$ & $\begin{array}{c}f, \mathrm{~Hz} \\
(\text { Case 6) }\end{array}$ \\
\hline 1 & 46.46 & 29.58 & 69.69 & 118.32 \\
2 & 106.97 & 36.91 & 160.46 & 147.64 \\
3 & 125.34 & 49.12 & 188.01 & 196.49 \\
4 & 185.85 & 66.22 & 278.77 & 264.88 \\
5 & 207.82 & 88.20 & 311.73 & 352.82 \\
6 & 256.80 & 111.0 & 385.20 & 443.99 \\
7 & 286.70 & 115.07 & 430.04 & 460.29 \\
8 & 317.31 & 118.32 & 475.96 & 473.30 \\
9 & 349.01 & 130.54 & 523.51 & 522.15 \\
10 & 418.16 & 146.83 & 627.23 & 587.31 \\
\hline
\end{tabular}

core and face layers, in terms of both materials selection and dimensions.

\section{Conclusions}

This study presents a mathematical method and framework on composite panels radiated sound and vibration. The panels are considered excited either by turbulent flow or by random noise. The turbulent flow corresponds to the typical excitation of an aircraft panel at flight cruise conditions, with a Mach number of 0.8 . The effect of type of panel, of panel dimensions, and of panel thickness are evaluated. The turbulent flow excitation showed to excite a higher number of panel modes compared to random noise excitation, and resulted in dissimilar levels of both panel vibration and radiated sound with relation to the random excitation. This effect is more visible for composite than for isotropic panels, and therefore the pure random noise should not be used as representative of the turbulent flow excitation in real applications.

Different properties on the composite panels are shown to yield dissimilar effects in the noise and vibration predictions. The effect of the panel size, specifically its length and width, is noted to have a significant effect on the panel performance in terms of noise radiation and vibration levels. Overall, smaller composite panels, or panels with higher aspect ratio, produced lower levels of radiated sound and vibration than longer and wider composite panels. Compared to isotropic panels, composite panels analyzed are shown to radiate lower noise levels, with the exception of specific natural frequencies which are amplified near $300 \mathrm{~Hz}$ and $1000 \mathrm{~Hz}$. It is shown that this amplification can be significant for composite panels with thicker face layers and thinner core layer, and thus resulting in unwanted effect of increased sound radiated. Despite this effect, this drawback may potentially be corrected by increasing the sandwich core layer thickness. Increasing the core layer thickness will impact the panel weight, and hence the composite panels can represent a heavier solution compared to the isotropic panels examined. On the other hand, this approach may be beneficial in the design of composite panels in the context of aircraft panel applications, since these panels may require less acoustic insulation material added to the aircraft walls, as they already represent an improved design solution. Furthermore, acoustic insulation materials have a higher impact in decreasing sound levels at the high frequency ranges, and therefore it will not significantly improve the problem of higher noise levels at the low frequency range, particularly observed in the isotropic solutions. In this context, advanced and optimized composite panel configurations may be a promising replacement to the traditional isotropic panels for aerospace applications.

\section{Conflict of Interests}

The author declares that there is no conflict of interests regarding the publication of this paper.

\section{Acknowledgment}

The author is grateful for the support of the National Science and Engineering Research Council of Canada.

\section{References}

[1] J. Rocha and D. Palumbo, "On the sensitivity of sound power radiated by aircraft panels to turbulent boundary layer parameters," Journal of Sound and Vibration, vol. 331, no. 21, pp. 47854806, 2012.

[2] J. Rocha, A. Suleman, and F. Lau, "Prediction of turbulent boundary layer induced noise in the cabin of a BWB aircraft," Shock and Vibration, vol. 19, no. 4, pp. 693-705, 2012.

[3] J. da Rocha, A. Suleman, and F. Lau, "Flow-induced noise and vibration in aircraft cylindrical cabins: closed-form analytical model validation," Journal of Vibration and Acoustics, vol. 133, no. 5, Article ID 051013, 9 pages, 2011.

[4] J. da Rocha, A. Suleman, and F. Lau, "Prediction of flow-induced noise in transport vehicles: development and validation of a coupled structural-acoustic analytical framework," Canadian Acoustics-Acoustique Canadienne, vol. 37, no. 4, pp. 13-29, 2009.

[5] G. Corcos, "The structure of the turbulent pressure field in boundary layer flows," Journal of Fluid Mechanics, vol. 18, pp. 353-378, 1964.

[6] G. Corcos, "Resolution of pressure in turbulence," Journal of the Acoustical Society of America, vol. 35, no. 2, pp. 192-199, 1963.

[7] B. Efimtsov, "Characteristics of the field of turbulent wall pressure fluctuations at large Reynolds numbers," Soviet Physics: Acoustics, vol. 28, no. 4, pp. 289-292, 1982.

[8] J. Reddy, Mechanics of Laminated Composite Plates and Shells: Theory and Analysis, CRC Press, Boca Raton, Fla, USA, 1945.

[9] J. Whitney, Structural Analysis of Laminated Anisotropic Plates, Technomic, Lancaster, Pa, USA, 1987.

[10] C. L. Dym and M. A. Lang, "Transmission of sound through sandwich panels," Journal of the Acoustical Society of America, vol. 56, no. 5, pp. 1523-1532, 1974.

[11] C. L. Dym, C. S. Ventres, and M. A. Lang, "Transmission of sound through sandwich panels: a reconsideration," Journal of the Acoustical Society of America, vol. 59, no. 2, pp. 364-367, 1976.

[12] S. Narayanan and R. L. Shanbhag, "Sound transmission through a damped sandwich panel," Journal of Sound and Vibration, vol. 80, no. 3, pp. 315-327, 1982. 
[13] C. L. Dym and D. C. Lang, "Transmission loss of damped asymmetric sandwich panels with orthotropic cores," Journal of Sound and Vibration, vol. 88, no. 3, pp. 299-319, 1983.

[14] S. Ghinet, N. Atalla, and H. Osman, "Diffuse field transmission into infinite sandwich composite and laminate composite cylinders," Journal of Sound and Vibration, vol. 289, no. 4-5, pp. 745778, 2006.

[15] J. Mendler, "Computational tool for the acoustic analysis of sandwich panels," in Proceedings of the European Conference on Noise Control (EURO-NOISE '95), Lyon, France, 1995.

[16] O. Foin, J. Nicolas, and N. Atalla, "An efficient tool for predicting the structural acoustic and vibration response of sandwich plates in light or heavy fluid," Applied Acoustics, vol. 57, no. 3, pp. 213-242, 1999.

[17] S. Assaf and M. Guerich, "Numerical prediction of noise transmission loss through viscoelastically damped sandwich plates," Journal of Sandwich Structures and Materials, vol. 10, no. 5, pp. 359-384, 2008.

[18] S. Assaf, M. Guerich, and P. Cuvelier, "Vibration and acoustic response of damped sandwich panels immersed in a light or heavy fluid," Computers and Structures, vol. 88, pp. 359-384, 2010.

[19] R. Zhou and M. J. Crocker, "Boundary element analyses for sound transmission loss of panels," Journal of the Acoustical Society of America, vol. 127, no. 2, pp. 829-840, 2010.

[20] K. Amichi, N. Atalla, and R. Ruokolainen, "A new 3D finite element sandwich plate for predicting the vibroacoustic response of laminated steel panels," Finite Elements in Analysis and Design, vol. 46, no. 12, pp. 1131-1145, 2010.

[21] F. Franco, S. de Rosa, and T. Polito, "Finite element investigations on the vibroacoustic performance of plane plates with random stiffness," Mechanics of Advanced Materials and Structures, vol. 18, no. 7, pp. 484-497, 2011.

[22] Y. Kim, "Identification of sound transmission characteristics of honeycomb sandwich panels using hybrid analytical/onedimensional finite element method," in Proceedings of the 35th International Congress and Exposition on Noise Control Engineering (INTER-NOISE '06), Honolulu, Hawaii, USA, 2006.

[23] F. Fahy, Sound and Structural Vibration, Radiation, Transmission and Response, Academic Press, London, UK, 1985.

[24] J. Blevins, Formulas for Natural Frequency and Mode Shape, Krieger Publishing, Malabar, Fla, USA, 2001.

[25] D. Newland, An Introduction to Random Vibration and Spectral Analysis, Longman, New York, NY, USA, 1984.

[26] Y. Lin, Probabilistic Theory of Structural Dynamics, McGrawHill Book, New York, NY, USA, 1967.

[27] C. E. Wallace, "Radiation resistance of a rectangular panel," The Journal of the Acoustical Society of America, vol. 51, no. 3, pp. 946-952, 1972. 

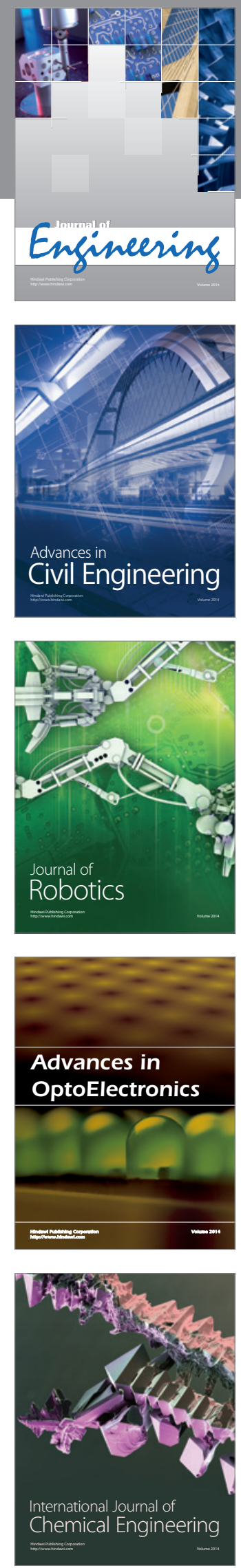

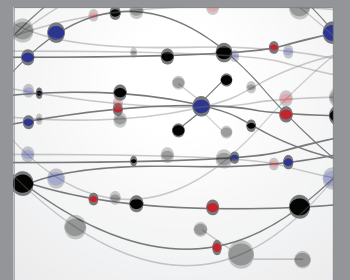

The Scientific World Journal
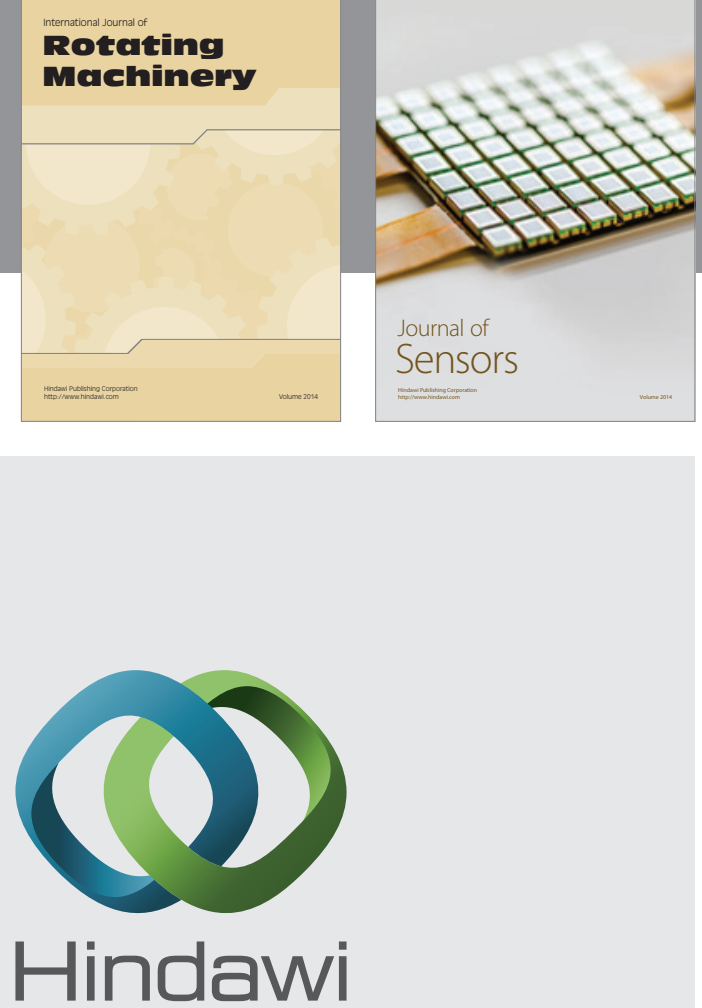

Submit your manuscripts at http://www.hindawi.com
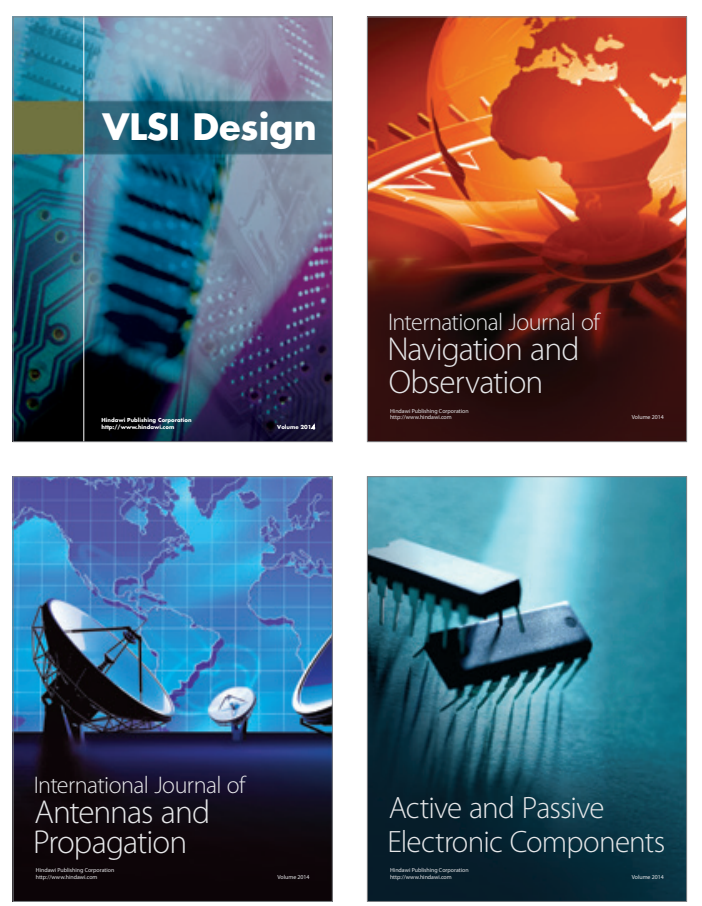
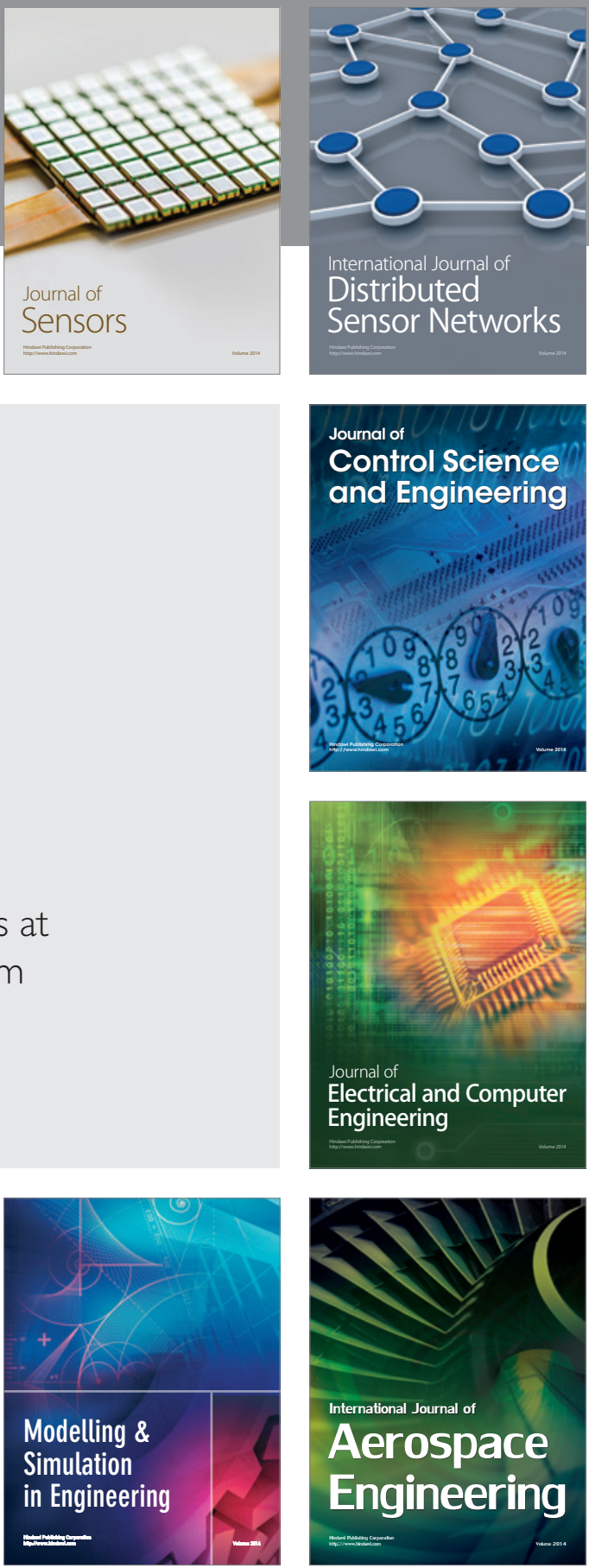

Journal of

Control Science

and Engineering
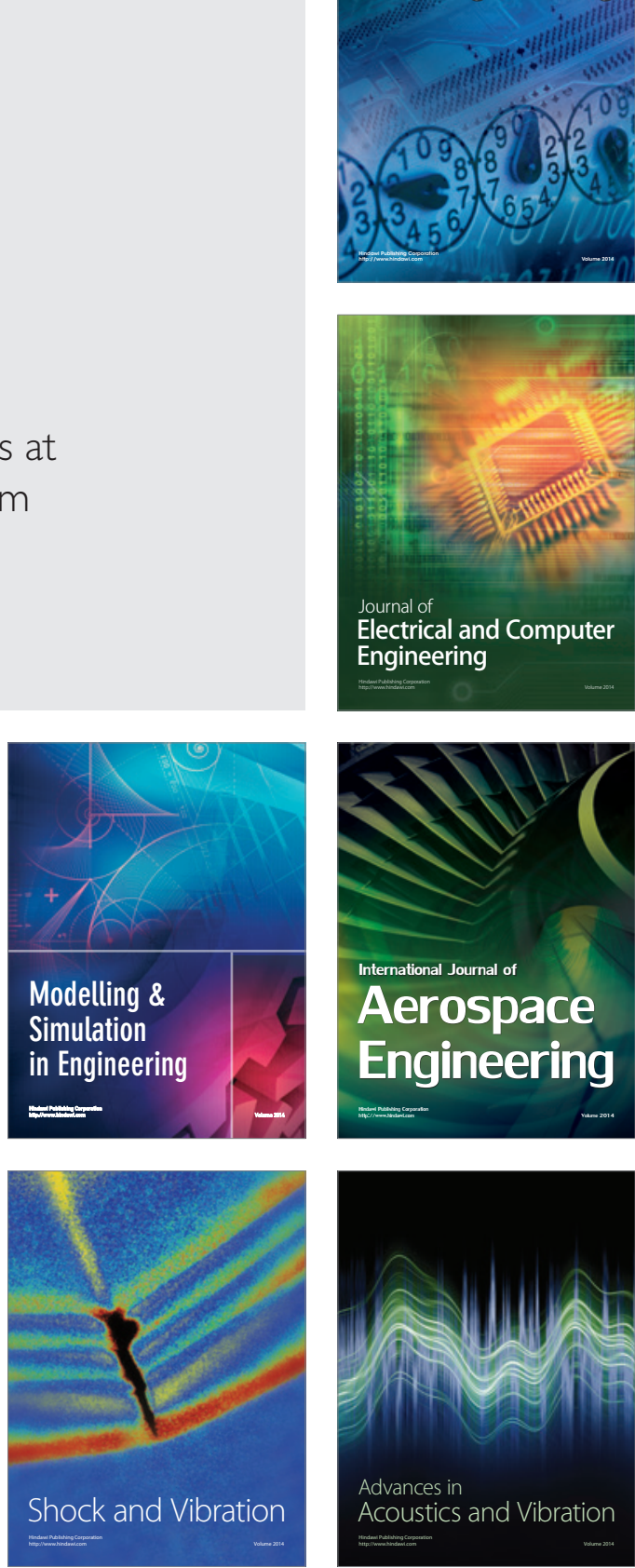